Supplement of Biogeosciences, 16, 3439-3455, 2019

https://doi.org/10.5194/bg-16-3439-2019-supplement

(C) Author(s) 2019. This work is distributed under

the Creative Commons Attribution 4.0 License.

(c) (1)

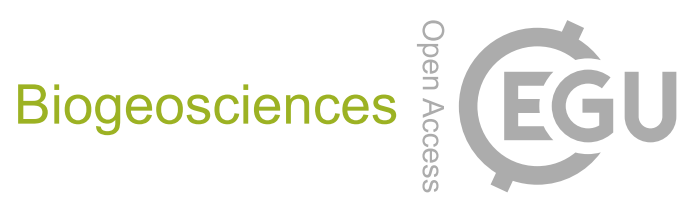

Supplement of

\title{
Insights into architecture, growth dynamics, and biomineralization from pulsed Sr-labelled Katelysia rhytiphora shells (Mollusca, Bivalvia)
}

Laura M. Otter et al.

Correspondence to: Laura M. Otter (laura.otter@mq.edu.au)

The copyright of individual parts of the supplement might differ from the CC BY 4.0 License. 
S1. Supplementary figures

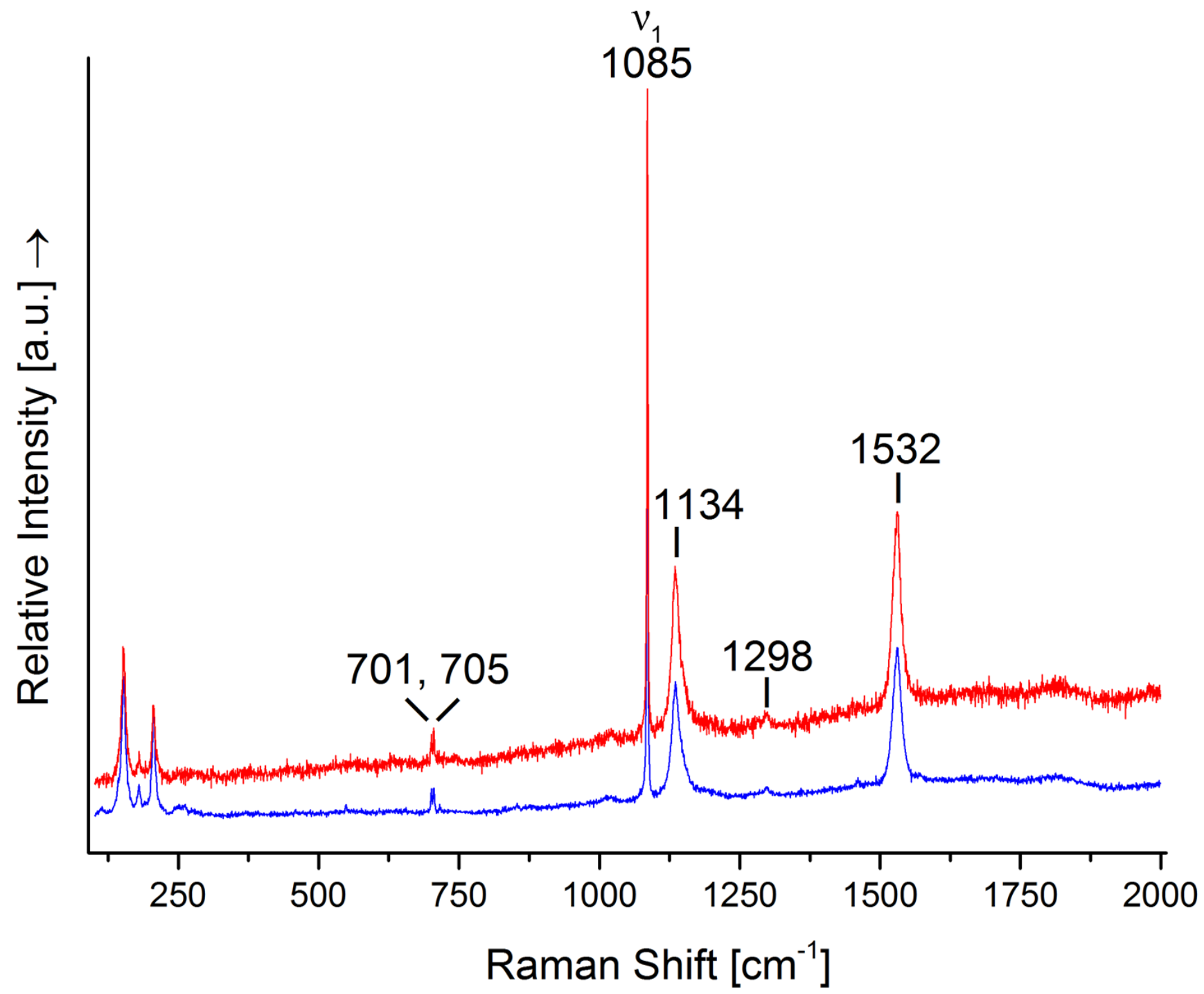

Figure S1: Representative micro-Raman spectra obtained from both ultrastuctures (iOSL-blue, oOSL-red). Relative Raman intensities were normalized to the highest intensity peak, no baseline correction. 


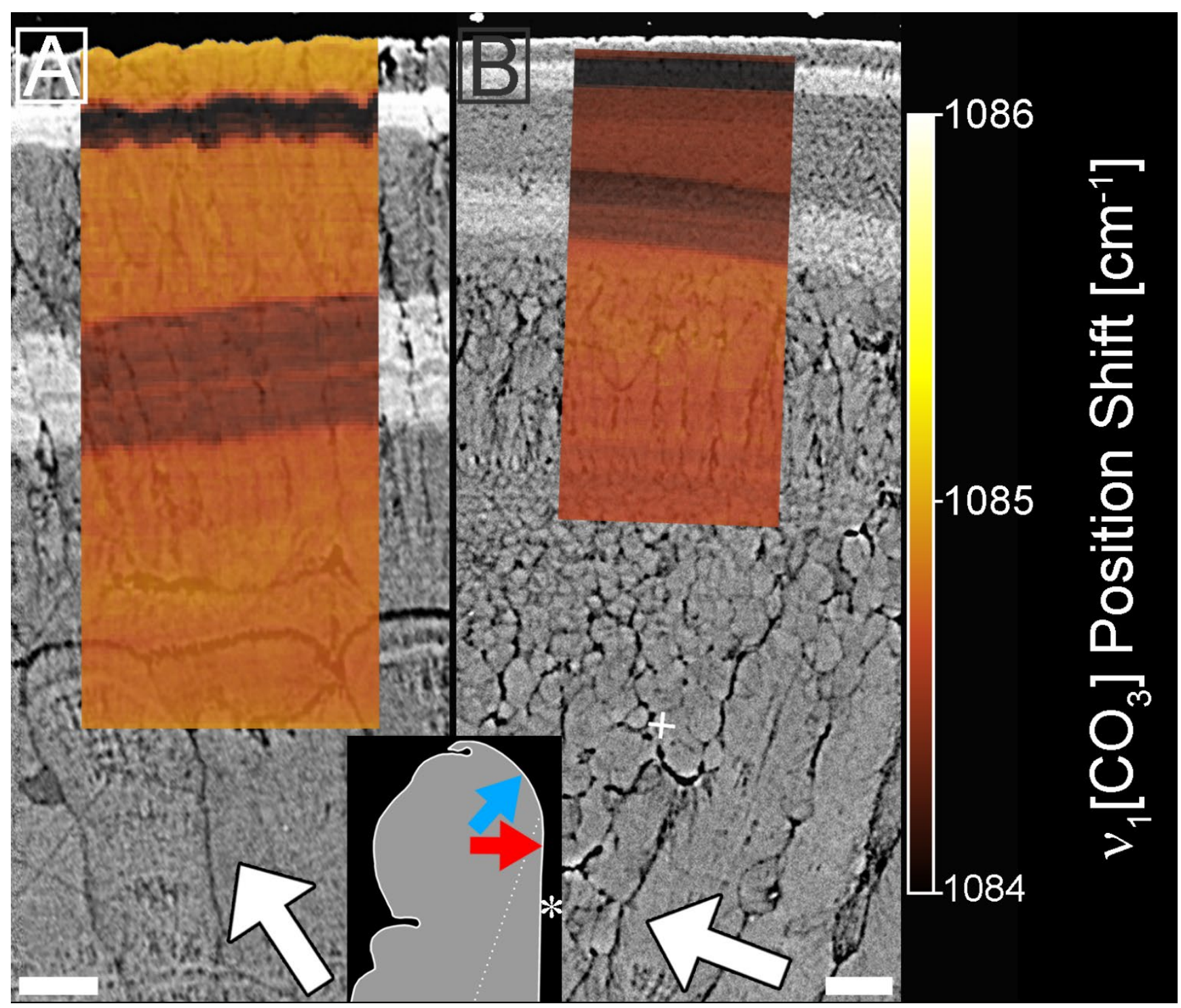

Figure S2: Micro-Raman maps overlain on BSE images of a polished cross-section of a Sr labelled $K$. rhytiphora shell showing the effect of variable $\mathrm{Sr}$ concentrations on the peak position of $v_{1}$ located at $1084.8 \mathrm{~cm}^{-1}$ in oOSL ((A) - compound composite prismatic ultrastructure) and iOSL ((B)- crossed-acicular architecture) Colour-scale on the right indicates the peak position and shift. All

5 cross-sections are prepared as radial sections along the maximum growth axis unless otherwise specified. Lighter grey areas in the BSE images have elevated Sr contents as confirmed by nanoSIMS and EPMA, and show excellent correlation with position shifts to lower wavenumbers of about $0.5 \mathrm{~cm}^{-1}$. White arrows indicate the general shell growth direction. The local growth direction is orthogonal to the light grey bands of the Sr-label in the BSE image. The inset shows a schematic of the shell tip with the location of the Raman maps (blue arrow - oOSL, red arrow - iOSL, dashed line marks the border between the layers), asterisk marks the inner shell surface. Scale bars are $10 \mu \mathrm{m}$. 


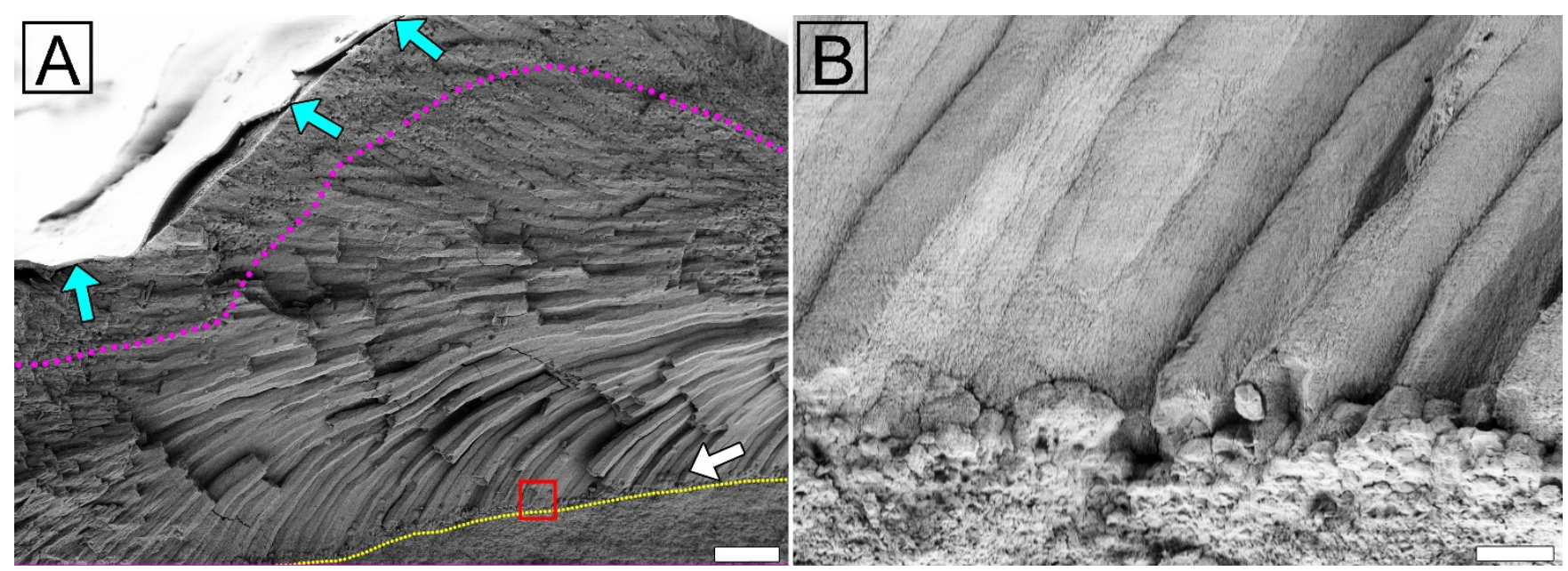

Figure S3: SE-images of a $K$. rhytiphora shell broken radially. Blue arrows in (A) point to well preserved areas of the thin periostracum (about $1 \mu \mathrm{m}$ thick). The pink dashed line marks a ca. $100 \mu \mathrm{m}$ wide zone of spherulitic aragonite grains adjacent to the periostracum. The yellow dashed line marks the boundary between the compound composite prismatic (oOSL) and crossed-acicular 5 (iOSL) ultrastructure. White arrow indicates the general growth direction of the shell. (B) magnification (red square in A) of the boundary between both layers shows spherulitic grains of up to $8 \mu \mathrm{m}$ in diameter. Scale bars are $100 \mu \mathrm{m}(\mathrm{A})$ and $10 \mu \mathrm{m}(\mathrm{B})$. 


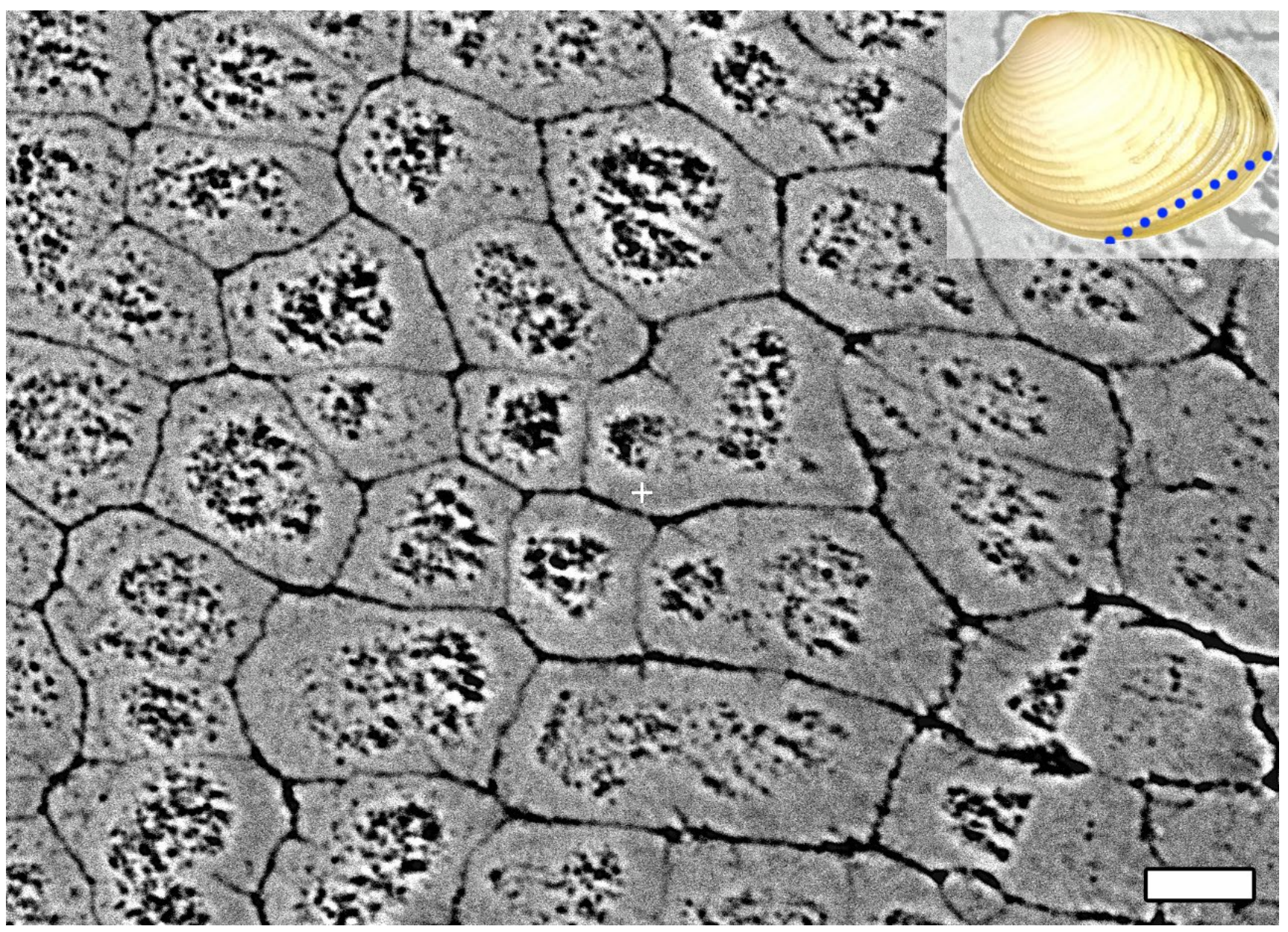

5 Figure S4: BSE image of a polished longitudinal cross-section of a K. rhytiphora shell. This orientation allows to observe first-order prisms (oOSL) perpendicular to their length axis (see sectioning plane indicated by blue dashed line in inset) for thickness measurements that average $17 \pm 5 \mu \mathrm{m}(\mathrm{n}=20)$. Prism centres appear dark and patchy, which results from the angled, 3D radial arrangement of second-order prisms, some of which are removed during polishing. Scale bar is $10 \mu \mathrm{m}$. 


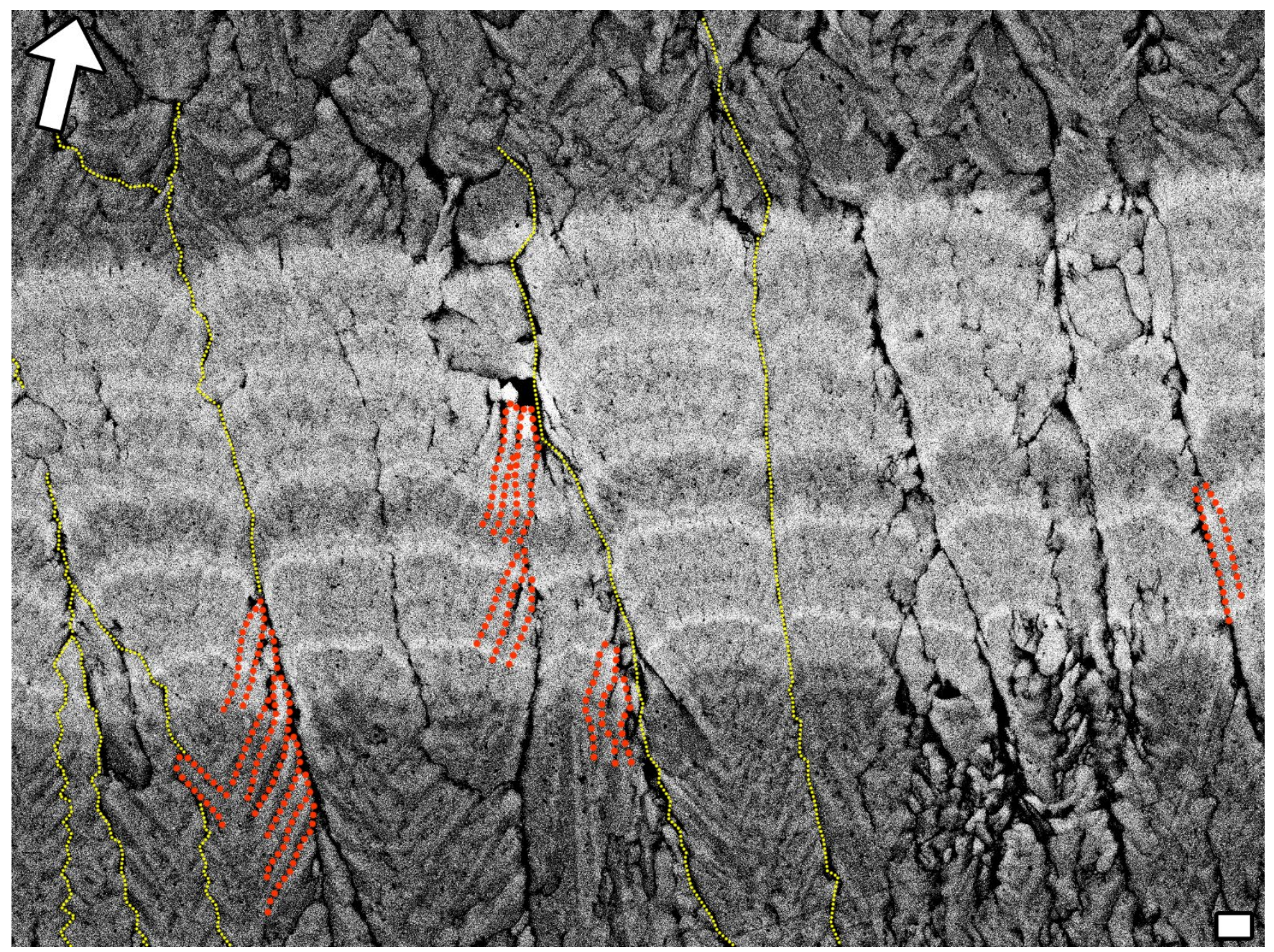

Figure S5: BSE image showing a polished cross-section of the innermost (first) Sr label (LE1) in the compound composite prismatic ultrastructure oOSL (sample K2-04). The Sr label appears as bright grey due to a higher Z-contrast. First-order prisms (yellow dotted lines) are separated by organic sheaths visible as dark grey. Second-order prisms (outlined in red) radiate from the central axis of first-order prisms and are $3 \pm 0.3 \mu \mathrm{m}$ long and $0.3 \pm 0.06 \mu \mathrm{m}$ wide $(\mathrm{n}=8)$. Note that these values are minimum values, since the base of each second-order prism is overlain by others. Maximum lengths can be up to twice those measured here. The angle between two second-order prisms facing each other is $68^{\circ}$. The thickness of the 6 day Sr label of $14 \mu \mathrm{m}$ and indicates that second-order prisms form over approx. 1.3 days during our experiments. A white arrow indicates the general growth direction of the shell, while the local growth direction is perpendicular to the Sr-labelled shell layer. Scale is $1 \mu \mathrm{m}$. 


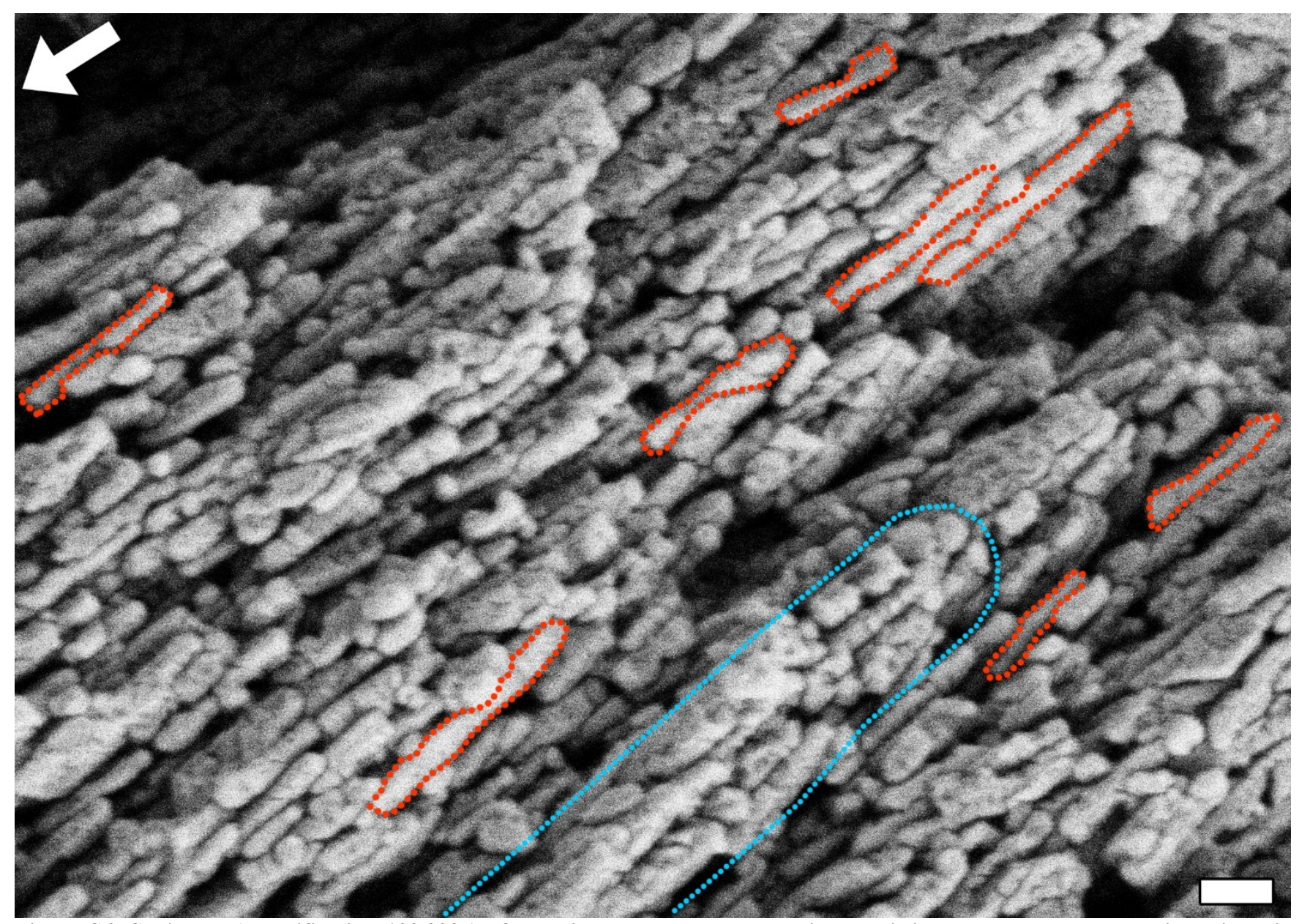

Figure S6: SE image (magnification 100,000x) of a radially broken shell exposing detail in the compound composite prismatic 5 ultrastructure (oOSL). Third-order prisms (outlined in red) are oriented parallel to each other within second-order prisms (outlined in blue). Fully exposed and unbroken third-order prisms were measured using ImageJ and are approx. $496 \pm 129 \mathrm{~nm}$ long and 67 $\pm 16 \mathrm{~nm}$ wide $(\mathrm{n}=8)$. These prismatic units are $28 \mathrm{x}$ shorter than the width of the Sr-labelled area of $14 \mu \mathrm{m}$, resulting in a growth rate of five third-order prisms per day during our experiments. The white arrow indicates the general growth direction of the shell. Scale bar is $200 \mathrm{~nm}$. 


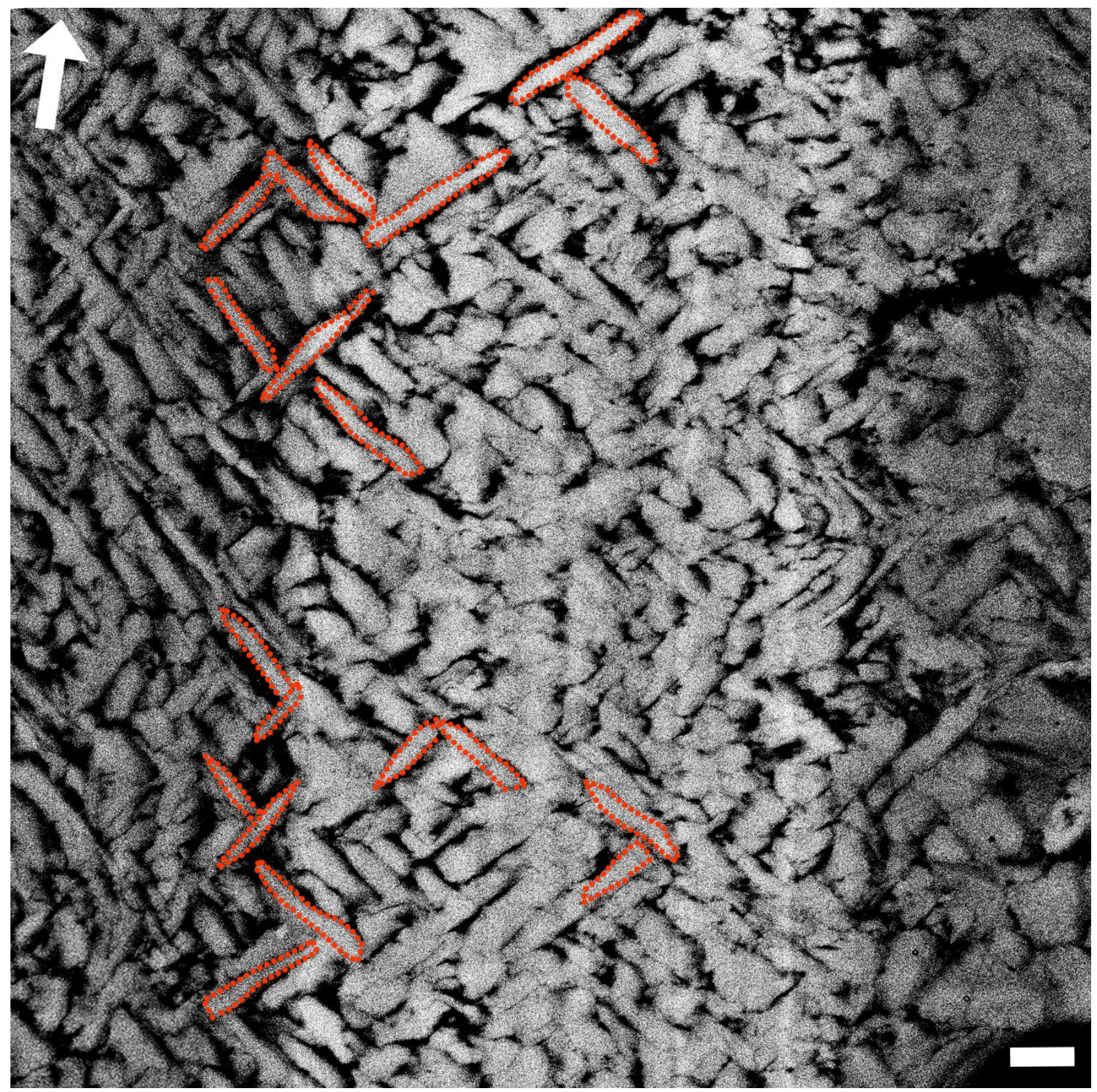

Figure S7: BSE image showing a polished cross-section of Sr label LE1 within the crossed-acicular ultrastructure (iOSL, sample K2-04). This architecture consists of elongated lamellae (outlined in red) arranged into intersecting bundles. Lengths and widths are $5 \quad 1.8 \pm 0.4 \mu \mathrm{m}$ and $0.22 \pm 0.05 \mu \mathrm{m}(\mathrm{n}=19)$, with an angle of $81^{\circ} \pm 8^{\circ}(\mathrm{n}=6)$. The projected length parallel to the general growth direction was calculated to be $1.2 \mu \mathrm{m}$. Using the relationship between the projected length of $1.2 \mu \mathrm{m}$ and the width of the LE1 label in this area $(=9 \mu \mathrm{m})$ acicular lamellae are deposited by constant rate of approximately 1 lamella/day during our experiments. The white arrow indicates the general growth direction of the shell, the local growth direction is perpendicular to the Sr label. Scale bar is 1 $\mu \mathrm{m}$. 


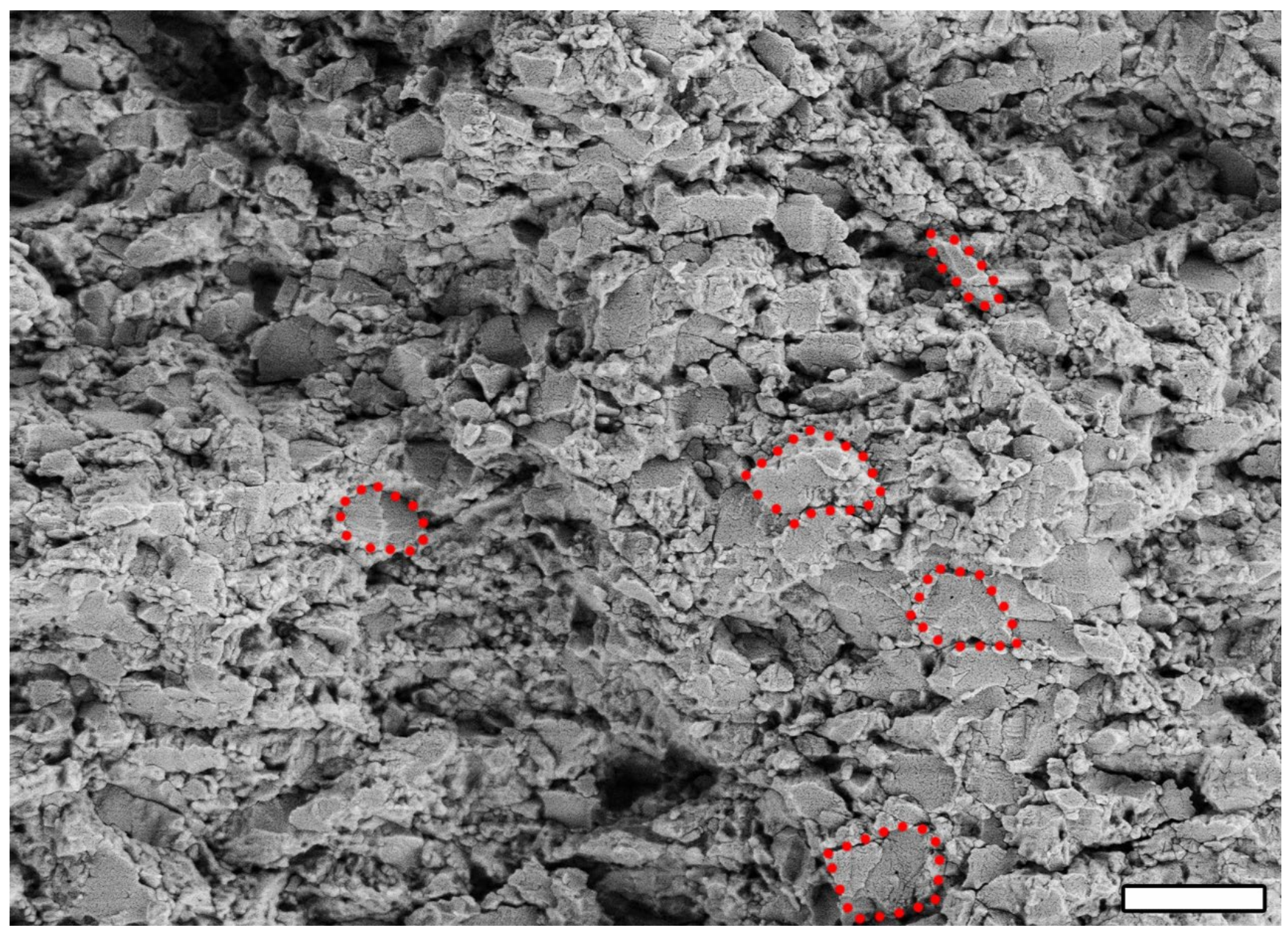

Figure S8: SE image showing a radially broken surface of the crossed-acicular ultrastructure (iOSL). In contrast to the BSE images, the crossed-acicular units appear here as bundles of lamellae (red dashed lines), while individual lamellae cannot be identified, because SE fails to visualize the organic sheaths around individual lamellae seen in BSE images (Figure S7). The bundles have sizes of around $1.4 \times 0.8 \times 0.2 \mu \mathrm{m}^{3}$. The general growth direction of the shell is identical to that in Fig. S3. Scale bar is $2 \mu \mathrm{m}$. 


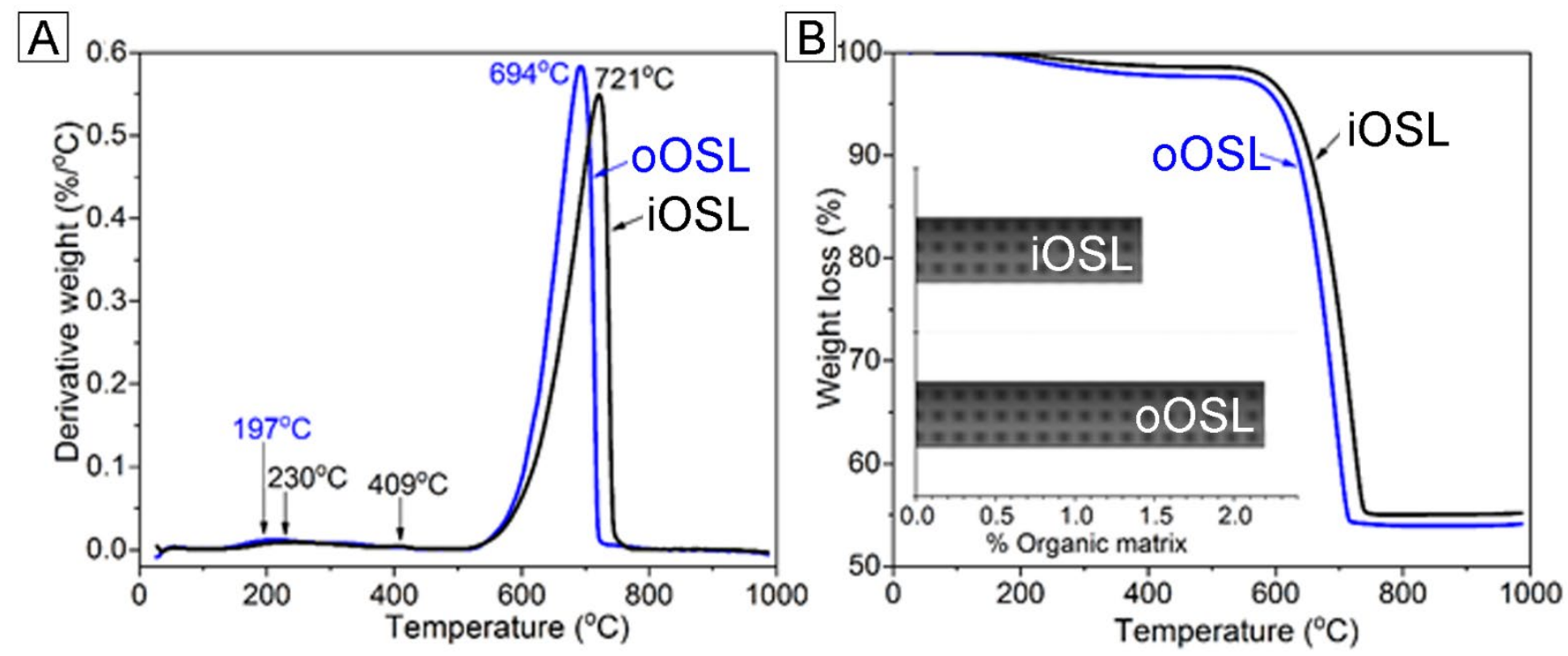

Figure S9: Differential thermal analysis (A) and thermal gravimetric analysis (B) show thermal stability and total organic matrix contents of iOSL and oOSL. Taking the inorganic $\mathrm{CO}_{2}$ content of $42-43 \%$ wt. $\%$ into account the organic matrix amounts to 1.42 5 wt.\% for the crossed-acicular ultrastructure (iOSL) and $2.19 \mathrm{wt}$ \% for the compound composite prismatic oOSL (inset in (B). 


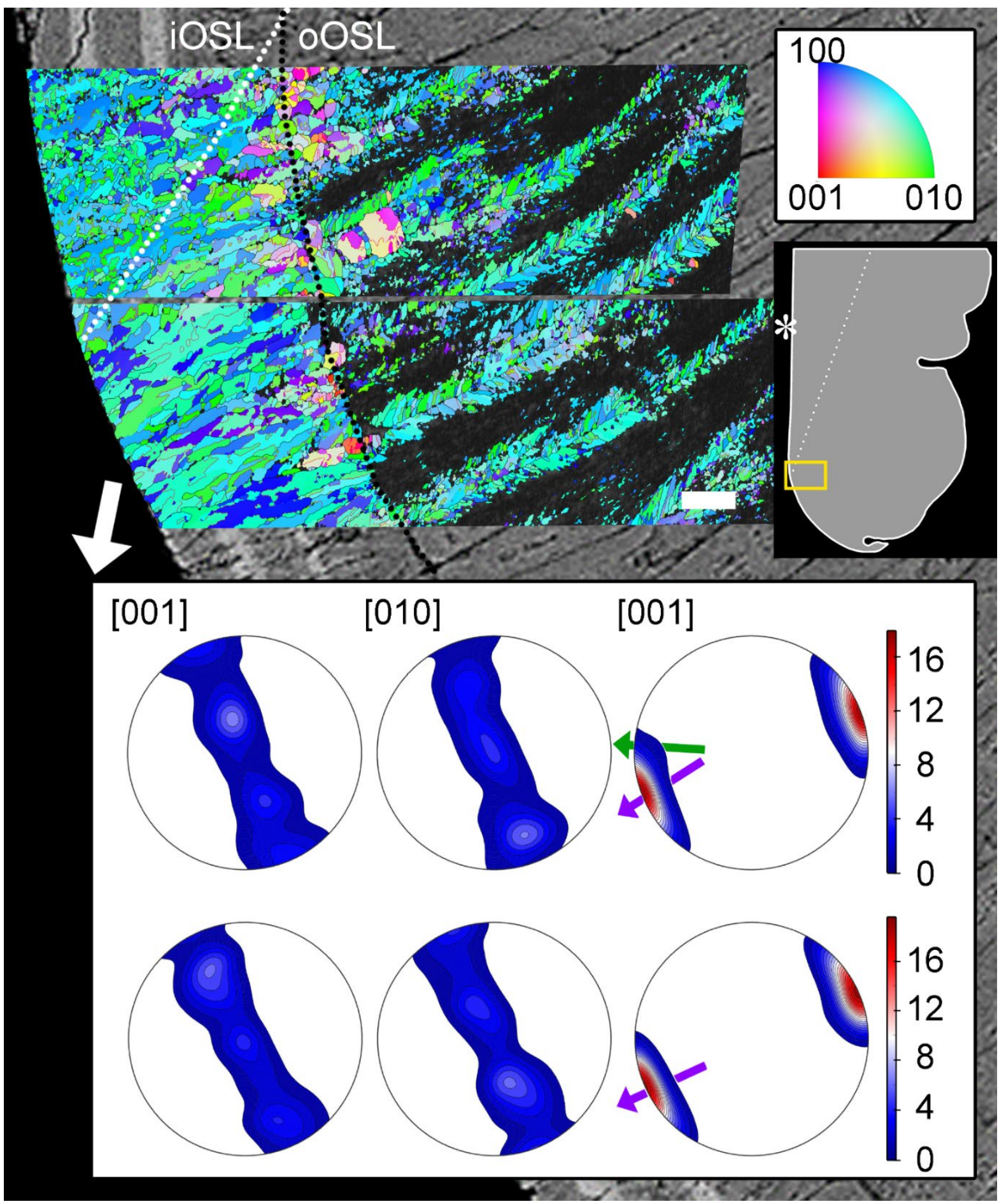

Figure S10: Orientation maps for aragonite (A) of a pulsed Sr-labelled shell (specimen ID: K2-11) overlain on BSE images of the shell area. The map consists of two adjacent individual maps that are colour-coded according to the inverse pole figure colouring scheme for orthorhombic aragonite: Blue, green, and red indicate the alignment of crystallographic a- [100], b- [010], and c-axes 5 [001], respectively. Further, the maps are color-coded to show the crystallographic orientation normal to the polished surface that 
vary randomly between the a-[100] and b-[010], while the c-axis [001] is aligned parallel with the local growth directions (i.e. perpendicular to the polished surface). Twinned grain boundaries are presented in red. The dotted white line outlines the boundary between oOSL and iOSL. Second-order prisms show a feathery arrangement within first-order prisms. Areas along the centres of first-order prisms in iOSL remain unindexed, which is likely an effect of damaging during sample polishing (see main text). The

5 organic growth check in the oOSL that transitions as a thin prismatic layer into the iOSL is highlighted with light black dotted lines. Pole figures (lower hemisphere, equal area projection) show the mineral fabric for [100], [010] and [001] axes of aragonite. The local growth direction of the prismatic oOSL (purple arrow in B) coincides with the shell layers visualised by pulsed Sr labelling in the underlying BSE image and is angled to the general shell growth direction (white arrow). The crystallographic c-axes [001] form a strong maximum of 18.70 times uniform (see scale bar on the right), while the a- ([100]) and b- ([010]) axes form a girdle of random orientations around the c-axes. This girdle corresponds to the direction of the growth lines that run perpendicular to the general shell growth direction. Compared to the pole figures for the lower orientation map, those for the upper EBSD map, show a small contribution of the crossed-acicular ultrastructure (iOSL) to the maximum of the c-axes (green arrow in B). A schematic of the cross-sectioned shell tip shows the location of the orientation maps and the underlying BSE image. Asterisk marks the inner shell surface. Scale bar is $10 \mu \mathrm{m}$. 


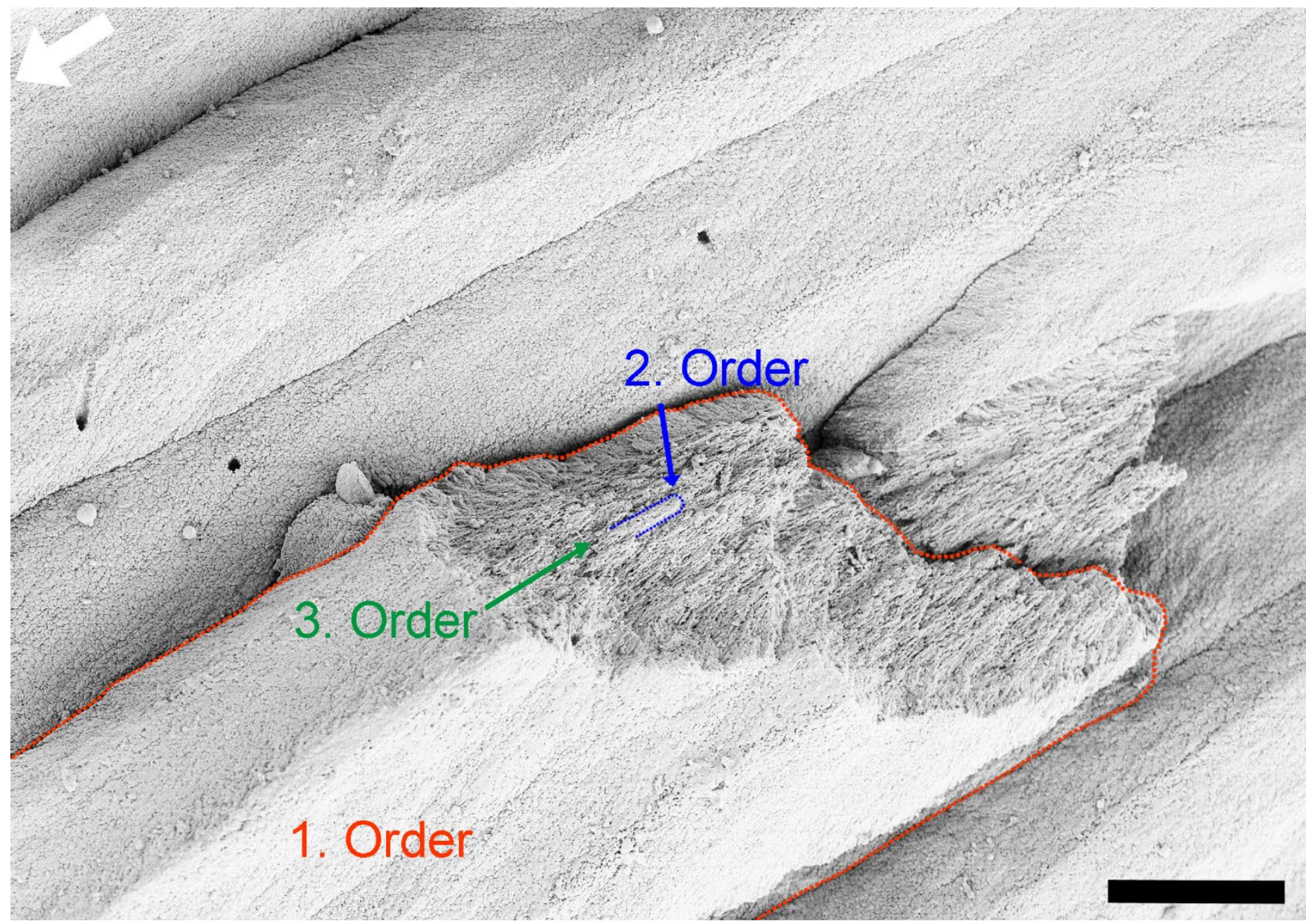

Figure S11: SE image showing a broken radial cross-section of the compound composite prismatic ultrastructure (oOSL). Firstorder prisms (outlined in red) have a compact internal architecture consisting of second-order prisms (outlined in blue) and thirdorder prisms (as fine-grained texture) are visible. The white arrow indicates the general growth direction of the shell. Scale bar is $10 \mu \mathrm{m}$. 


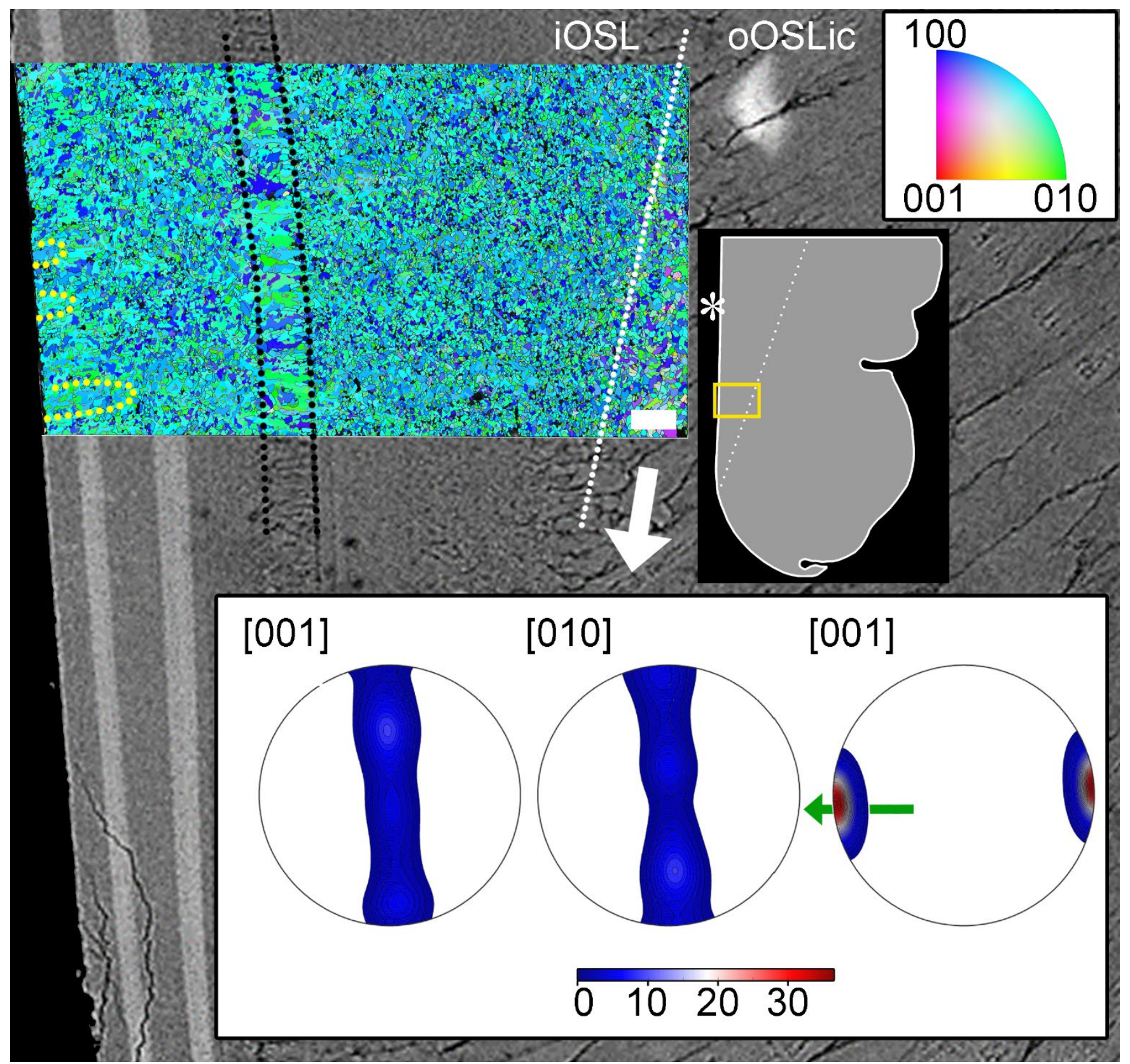

Figure S12: Orientation map (A) of a pulse Sr-labelled shell (specimen ID: K2-11) overlain on a correlated BSE image. The map is color-coded to show the crystallographic orientation normal to the polished surface that vary randomly between the a-[100] and b[010], while the c-axis [001] is aligned parallel with the local growth directions (i.e. perpendicular to the polished surface). Twinned

5 grain boundaries are presented in red. The boundary between crossed-acicular (iOSL) and compound composite prismatic (oOSL) architectures is marked by a dashed white line. The dashed black lines highlight the mineralized growth check (a thin prismatic layer) that continues from the organic growth check in the oOSL. At the inner shell surface pseudo-prisms (co-orientated areas, outlined in yellow) can be seen (Pérez-Huerta et al., 2014). Pole figures (lower hemisphere, equal area projection) show the alignment of the EBSD data with the [100], [010] and [001] axes of aragonite and exhibit a strong crystallographic preferred orientation (CPO)

10 of the crystallographic c-axis of aragonite [001]. The local direction of growth for the crossed-acicular ultrastructure (green arrow in B) is perpendicular to the light grey Sr labels in the underlying BSE image and, at this specific locality in the shell, differs by ca. 
$90^{\circ}$ from the general shell growth direction (white arrow). Similar to the oOSL in Fig. S10, the data forms a narrow girdle of random orientations for the $[100]$ and $[010]$ directions parallel to the growth lines running perpendicular to the general shell growth direction. Maximum density value for the [001] axes is 36.49 times uniform, thus exceeding significantly the value of the prismatic ultrastructure (oOSL, Fig. S10). A schematic of the shell tip shows the location of the orientation map and the BSE image. Asterisk 5 marks the inner shell surface. Scale bar is $10 \mu \mathrm{m}$. 


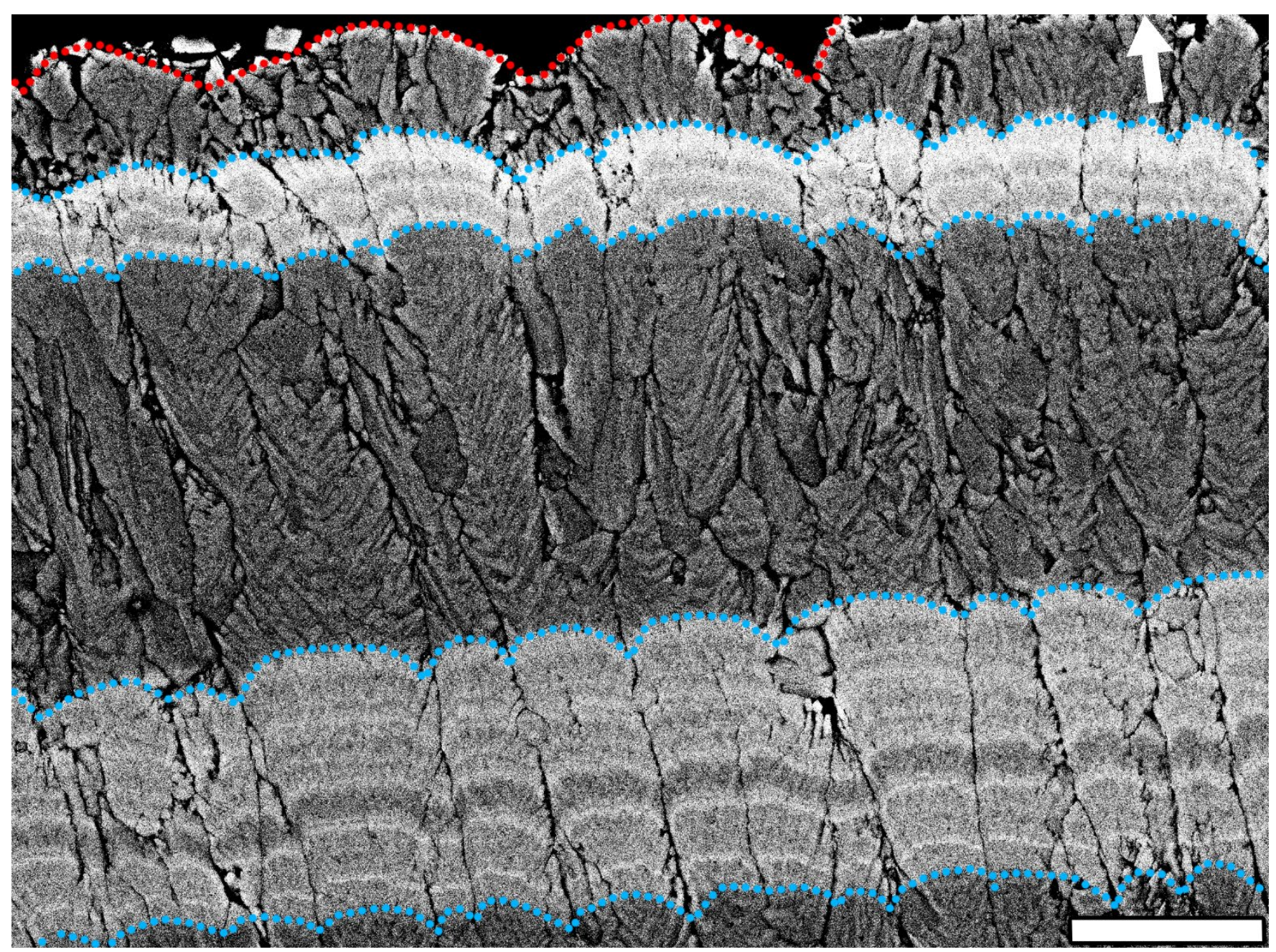

Figure S13: First-order prisms (separated by organic sheaths) have undulated (red line follows inner shell surface, blue line shows same undulating pattern at beginning and end of Sr-label) growth fronts with the individual apex co-aligned with the centre of each prism. A white arrow indicates the general growth direction of the shell, while the local growth direction is perpendicular to the Srlabelled shell layer. Scale bar is $10 \mu \mathrm{m}$. 


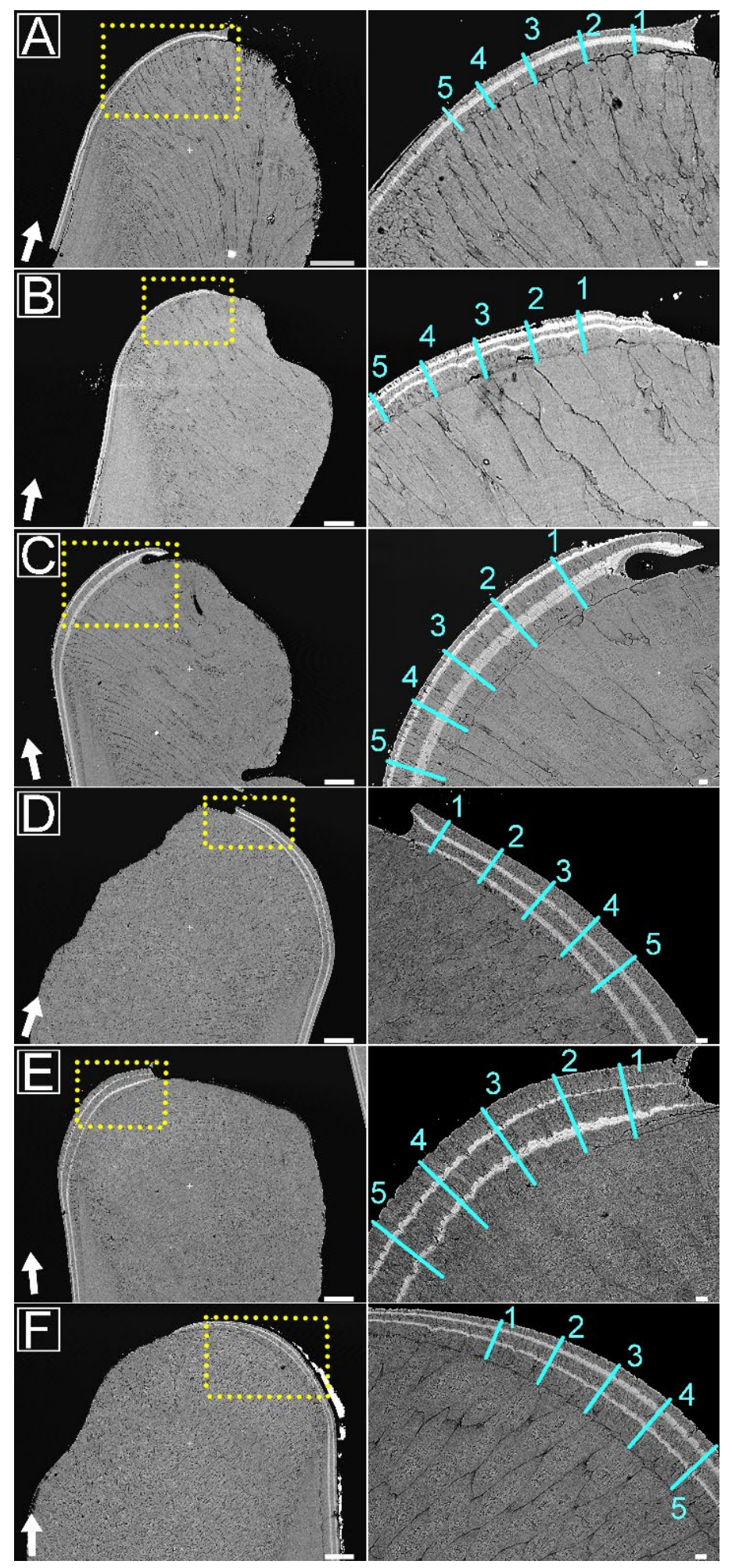

Figure S14: BSE images of polished cross-sections of compound composite prismatic shell at the growth front of the ventral margin. Overview images (left column) as well as higher magnification images of areas marked in yellow (right column). Blue numbered lines indicate where local growth rate measurements were obtained (Suppl. Table 4, for averages see Table 2). Specimens used are K2-01 (A), K2-02 (B), K2-04 (C), K2-06 (D), K2-08 (E), and K2-11 (F). Specimens K2-10 and K2-14 are excluded here as they showed different perturbations at this growth front. White arrows indicate the general growth direction for each shell, while the individual local growth direction is perpendicular to the Sr-label in light gray. Scale bars: $100 \mu \mathrm{m}$ for left column and $10 \mu \mathrm{m}$ for right column images. 

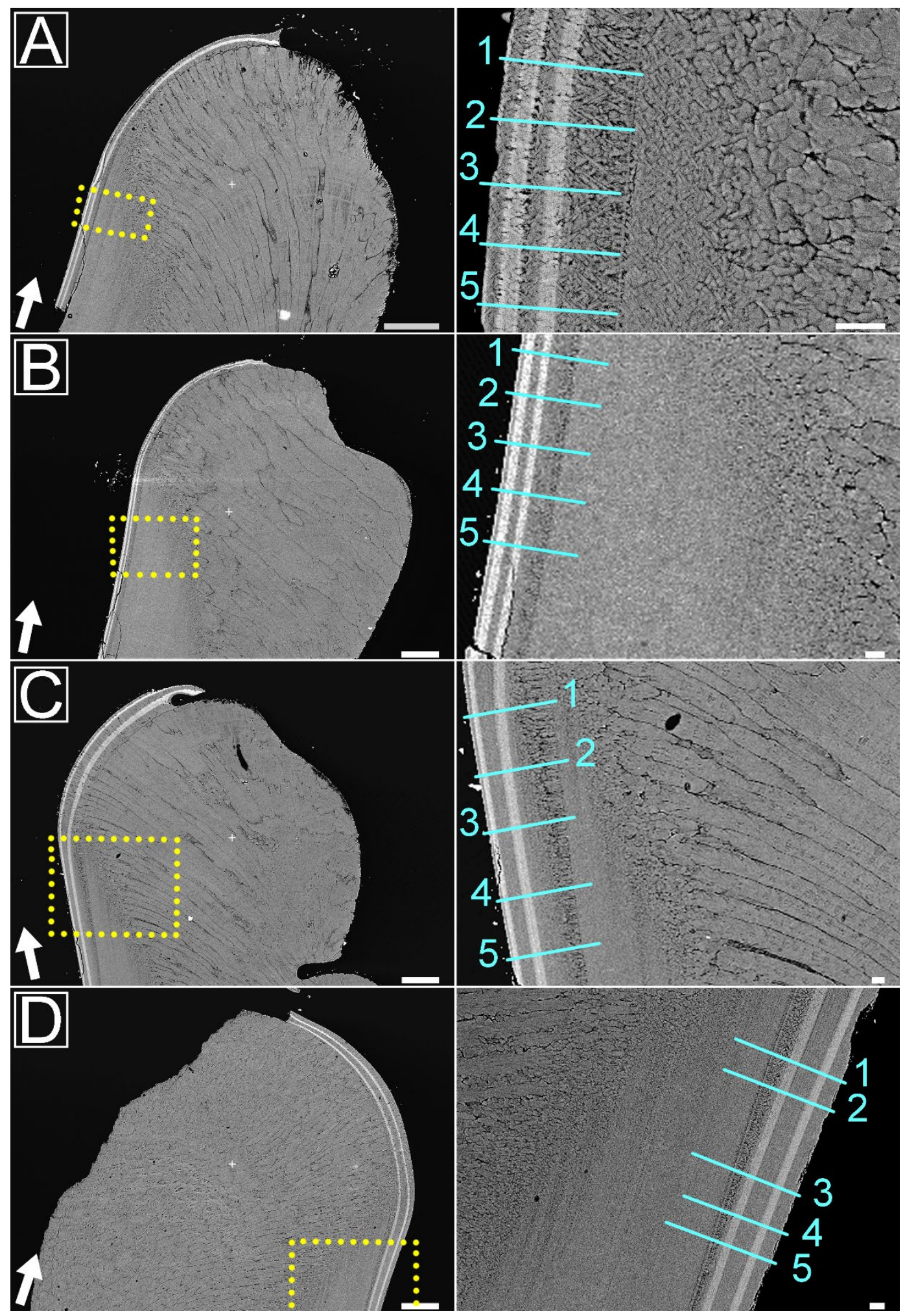
(Fig. S15 Continued)

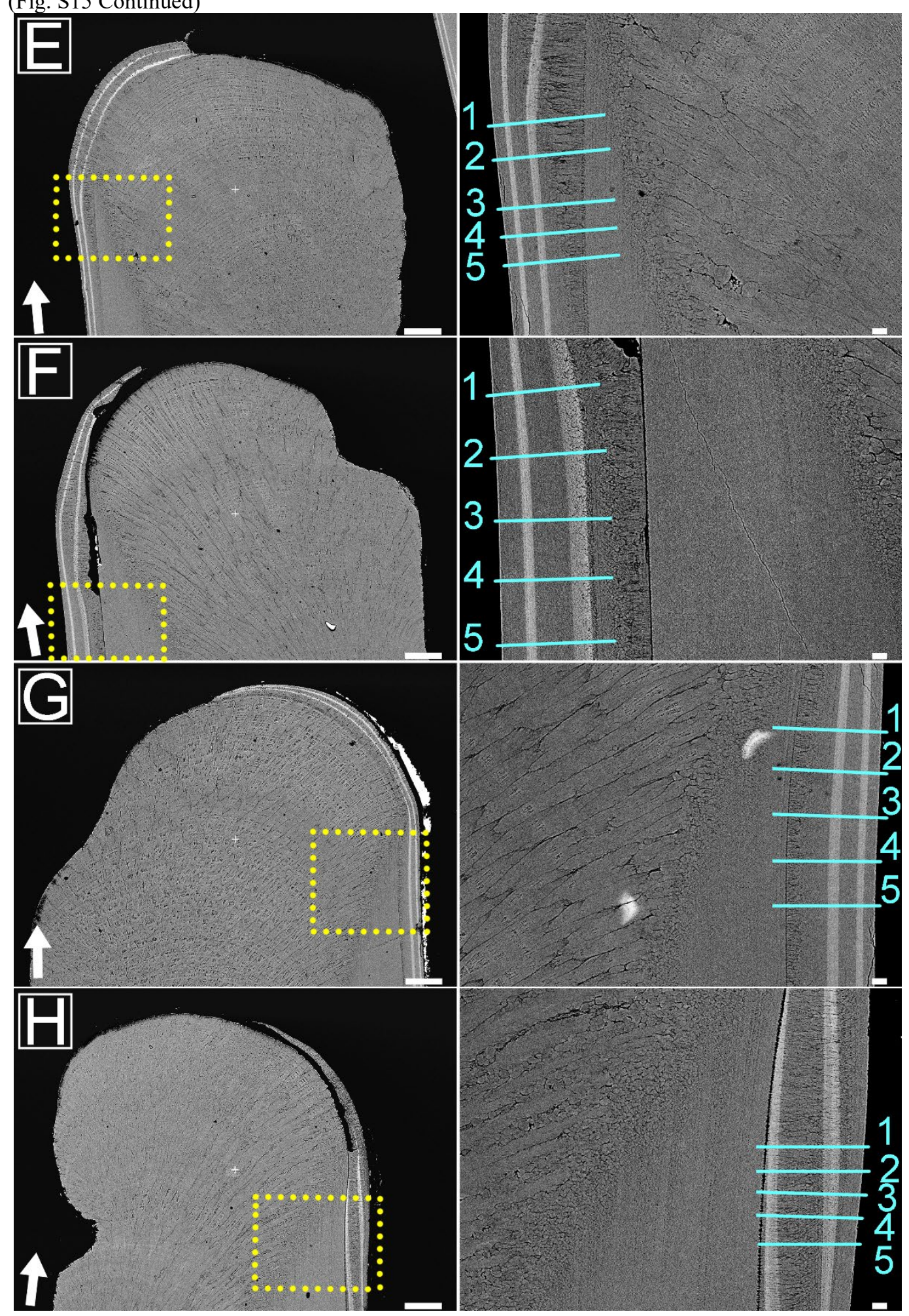



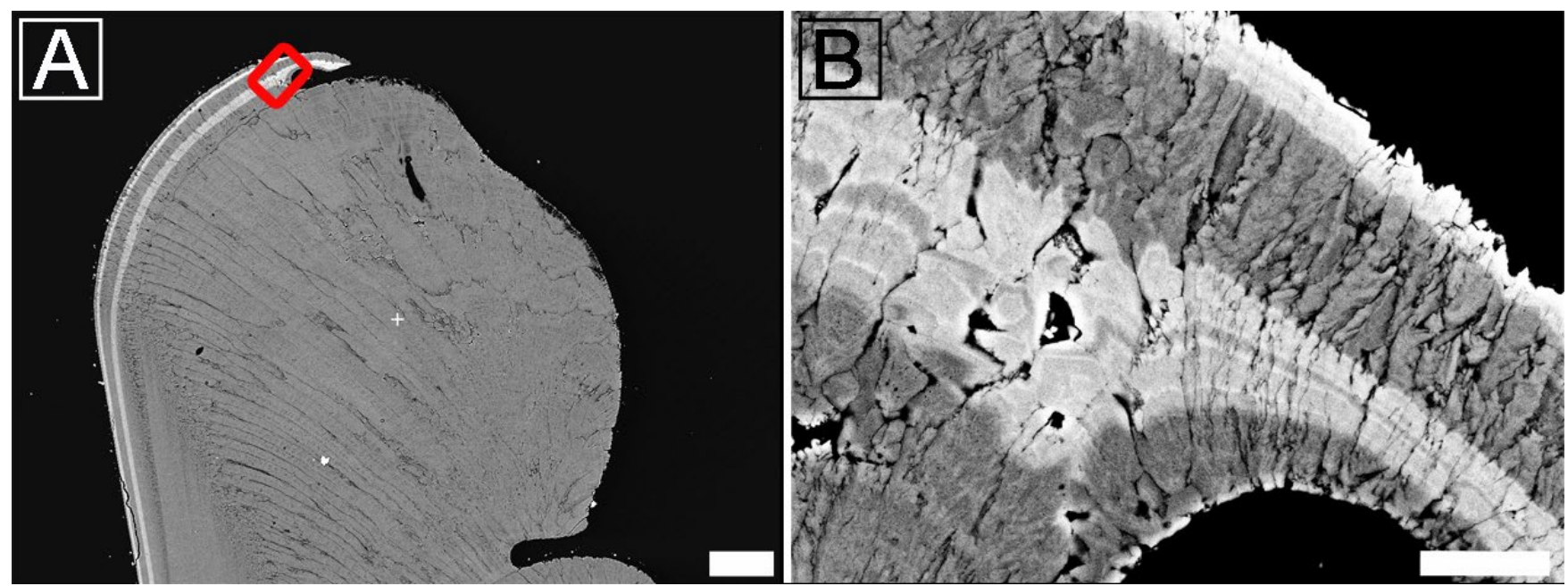

Figure S16: BSE images of a polished cross-section (sample K2-04) (A). (B) shows an enlarged area marked by the red box in (A). It can be clearly seen how the new ridge feature formed as a consequence of very high short-term local growth rate as the label is thicker here, likely, to stabilize the fragile new tip area. See Fig. S15C for general growth direction of the shell, while the individual local growth direction is perpendicular to the Sr-label in light gray. Scale bars are $100 \mu \mathrm{m}(\mathrm{A})$ and $10 \mu \mathrm{m}(\mathrm{B})$. 

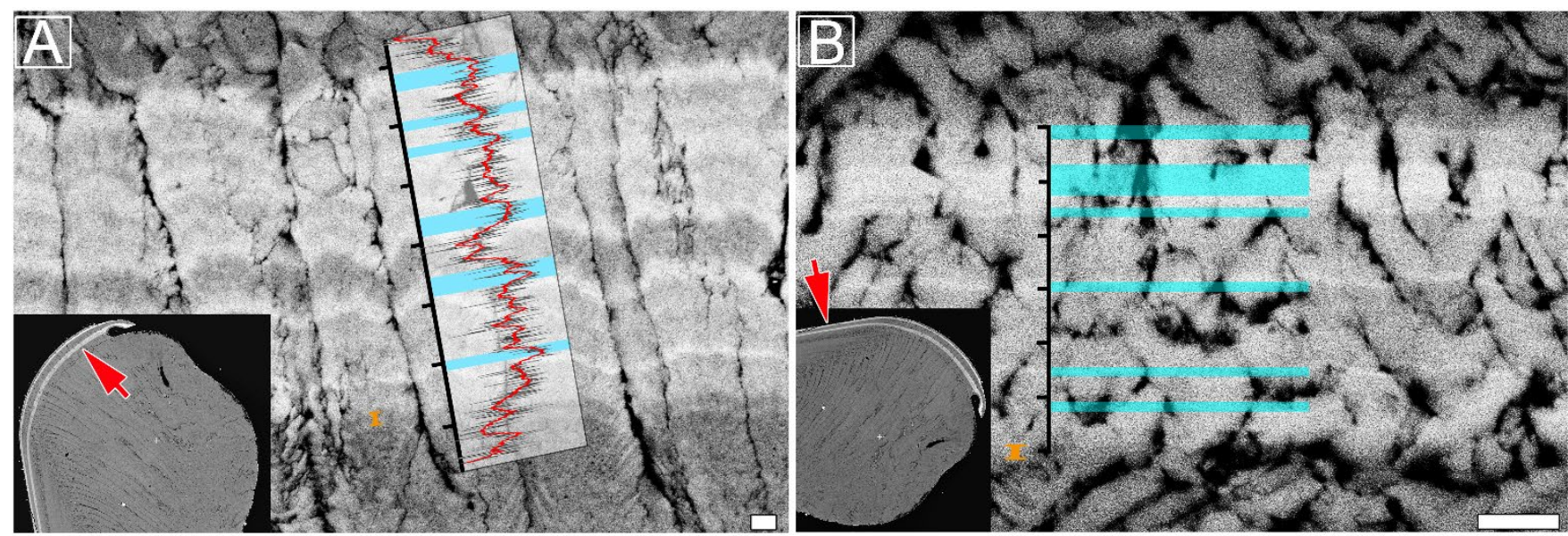

Figure S17: BSE images of polished cross-sections of a Sr-labelled shell (sample K2-04). In the compound composite prismatic layer (oOSL), both Sr labels LE1 (A) and LE2 (B) consist of several narrow increments of varying bright greyscales. Similar patterns are observed in the crossed-acicular layer (iOSL) for LE1 (C) and LE2 (D) Comparison with micro-Raman maps (Fig. 3) supports differences in Sr contents between these micro-increments of different grey scales. Line profile insets of BSE greyscale intensities for LE1 (A) reveal six distinct peaks. Generally, brighter greyscale areas correlating with the peaks in the line scans are significantly thinner than the darker areas between them. Differences in intensity and width of increments observed within the labels are suggested to result from metabolic activity, perhaps with higher growth rates incorporating higher amounts of Sr (as peaks) followed by wider intervals of lower Sr concentration, due to lower growth rates. The crossed-acicular ultrastructure (iOSL) shows similar patterns (B) that are highlighted by blue lines after visual examination. This approach was chosen since it is not possible to obtain line-profiles across these labels as the organic sheaths surrounding the lamellae distort the line profiles severely. A ca. $500 \mathrm{~nm}$ narrow greyscale transition in for the oOSL in (A) (ca. $150 \mathrm{~nm}$ in the iOSL (B)) is highlighted in orange and depicts shell growth in the range of 5 hours calculated by the local daily growth rates of Table 2. See Fig. S15C for general growth direction of the shell, while the Srlabelled shell layers show the local growth directions at this particular site. Scale bars are $1 \mu \mathrm{m}$. 
S2. Supplementary tables

Table S1: WDX Electron Probe Micro Analyser (EPMA) parameters.

\begin{tabular}{|c|c|}
\hline Routine: & "Biocarb" protocol: \\
\hline Accelerating Voltage: & $15 \mathrm{kV}$ \\
\hline Beam Current: & $8 \mathrm{nA}$ \\
\hline Spot Size: & Scanning at 20000 magnification \\
\hline Elements and lines used: & 11 \\
\hline $\mathrm{Na} \mathrm{K} \alpha$ & Albite \\
\hline - $\quad \operatorname{Mg~K} \alpha$ & Dolomite \\
\hline - $\quad \mathrm{P} \mathrm{K} \alpha$ & Apatite \\
\hline - $\quad \mathrm{S} \mathrm{K} \alpha$ & $\mathrm{BaSO}_{4}$ \\
\hline - $\quad \mathrm{Cl} \mathrm{K} \alpha$ & Tugtupite \\
\hline $\mathrm{K} \mathrm{K} \alpha$ & Orthoclase \\
\hline - $\quad \mathrm{Ca} \mathrm{K} \alpha$ & $\mathrm{CaCO}_{3}$ \\
\hline $\mathrm{Mn} \mathrm{K \alpha}$ & Rhodochrosite \\
\hline - $\quad \mathrm{Fe} \mathrm{K} \alpha$ & $\mathrm{Fe}_{2} \mathrm{O}_{3}$ \\
\hline - $\quad \operatorname{Sr} L \alpha$ & $\mathrm{SrSO}_{4}$ \\
\hline - $\quad B a L \alpha$ & $\mathrm{BaSO}_{4}$ \\
\hline
\end{tabular}


Table S2: Geochemical composition of K. rhytiphora shells obtained from wavelength-dispersive X-ray spectrometry (WDS) electron probe micro analyser (EPMA) as wt.\% (g· $\mathrm{g}^{-1}$ ) averages (Avg.) and standard deviations (Stdev.). Shell increments listed are those grown in the wild ("pre-aqua"), in aquaculture during pulsed Sr-labelling ("LE 1" and "LE 2"), and non-labelling ("pre-NE 1" and "NE 1").

\begin{tabular}{|c|c|c|c|c|c|c|c|c|}
\hline & & & $\mathrm{Na}_{2} \mathrm{O}$ & MgO & $\mathrm{SO}_{3}$ & $\mathrm{Cl}$ & $\mathrm{CaO}$ & SrO \\
\hline \multirow{10}{*}{ 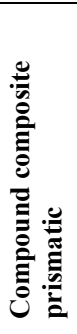 } & \multirow{2}{*}{$\begin{array}{c}\text { Pre-Aqua } \\
(\mathrm{n}=5)\end{array}$} & Avg. & 0.72 & 0.03 & 0.10 & 0.04 & $\begin{array}{l}54.38 \\
\end{array}$ & 0.12 \\
\hline & & Stdev & 0.06 & 0.02 & 0.04 & 0.01 & 0.20 & 0.03 \\
\hline & \multirow{2}{*}{$\begin{array}{c}\text { Pre-LE } 1 \\
(\mathrm{n}=3)\end{array}$} & Avg. & 0.57 & 0.04 & 0.14 & 0.04 & 54.73 & 0.13 \\
\hline & & Stdev & 0.04 & 0.01 & 0.03 & 0.01 & 0.07 & 0.01 \\
\hline & \multirow{2}{*}{$\begin{array}{l}\text { LE 1 } \\
(\mathrm{n}=3)\end{array}$} & Avg. & 0.56 & 0.04 & 0.12 & 0.03 & 52.86 & 2.36 \\
\hline & & Stdev & 0.04 & 0.01 & 0.02 & 0.01 & 0.09 & 0.07 \\
\hline & \multirow{2}{*}{$\begin{array}{l}\text { NE 1 } \\
(\mathrm{n}=3)\end{array}$} & Avg. & 0.41 & 0.03 & 0.17 & 0.03 & 54.72 & 0.16 \\
\hline & & Stdev & 0.01 & 0.03 & 0.05 & 0.02 & 0.43 & 0.01 \\
\hline & \multirow{2}{*}{$\begin{array}{c}\text { LE 2 } \\
(\mathrm{n}=3)\end{array}$} & Avg. & 0.65 & 0.04 & 0.12 & 0.02 & 53.80 & 2.29 \\
\hline & & Stdev & 0.04 & 0.01 & 0.03 & 0.01 & 0.15 & 0.02 \\
\hline \multirow{9}{*}{ 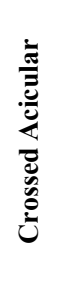 } & \multirow{2}{*}{$\begin{array}{l}\text { Pre-Aqua } \\
\quad(\mathrm{n}=5)\end{array}$} & Avg. & 0.75 & bdl & 0.05 & 0.02 & 54.01 & 0.11 \\
\hline & & Stdev & 0.09 & - & 0.06 & 0.01 & 0.06 & 0.04 \\
\hline & \multirow{2}{*}{$\begin{array}{c}\text { Pre-LE } 1 \\
(\mathrm{n}=3)\end{array}$} & Avg. & 0.77 & bdl & 0.05 & 0.02 & 53.76 & 0.10 \\
\hline & & Stdev & 0.09 & - & 0.03 & 0.02 & 0.07 & 0.04 \\
\hline & \multirow{2}{*}{$\begin{array}{c}\text { LE 1" } \\
(\mathrm{n}=3)\end{array}$} & Avg. & 0.75 & bdl & 0.13 & 0.03 & 53.18 & $>1.43$ \\
\hline & & Stdev & 0.09 & - & 0.07 & 0.01 & 0.06 & 0.04 \\
\hline & \multirow{2}{*}{$\begin{array}{c}\text { NE 1* } \\
(\mathrm{n}=3)\end{array}$} & Avg. & 0.72 & 0.03 & 0.20 & 0.02 & 54.52 & 0.15 \\
\hline & & Stdev & 0.09 & 0.05 & 0.07 & 0.02 & 0.06 & 0.04 \\
\hline & \multicolumn{2}{|c|}{ Limits of Detection: } & 0.05 & 0.02 & 0.04 & 0.01 & 0.04 & 0.02 \\
\hline
\end{tabular}

$\mathrm{MnO}(<0.025), \mathrm{BaO}(<0.018), \mathrm{P}_{2} \mathrm{O}_{5}(<0.028), \mathrm{K}_{2} \mathrm{O}(<0.017)$, and $\mathrm{FeO}(<0.020)$, were analysed and always below detection limits (provided 5 in brackets as wt.\%). *LE2 and NE 2 in the crossed acicular ultrastructure (iOSL) were too close to the inner shell surface and are excluded, while LE1 is presented as a minimum value as the analysed area slightly exceeds the label width. 
Table S3: Raman band parameters of $v_{1}\left[\mathrm{CO}_{3}\right]$ as obtained from micro-Raman hyperspectral mapping of Sr labelled and unlabelled aragonite of the compound composite prismatic (oOSL) and crossed-acicular (iOSL) shell layers. FWHM distributions are shown in Fig. 3, while Raman band positions shifts are shown in Supplementary Fig. 3. Averages from spectra from labelled and unlabelled regions $(\sim 25$ $\mu \mathrm{m}^{2}$ ) are given (Ø) together with minimum and maximum values of multiple spots (spot size $2.25 \mu \mathrm{m}^{2}$ ) and reflect subtle changes within respective layers. All FWHM values were corrected following the equation of Váczi (2014).

\begin{tabular}{|c|c|c|c|c|c|}
\hline & Sample Area: & & & $\mathrm{Ra}$ & $\left.\mathrm{cm}^{-1}\right]$ \\
\hline & LE 1 & $\varnothing$ & 1.9 & $\varnothing$ & 1084.5 \\
\hline ש & & Max: & 2.7 & Max: & 1084.8 \\
\hline$\widetilde{\Xi}$ & & Min: & 1.7 & Min: & 1084.6 \\
\hline 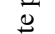 & NL 1 & $\varnothing$ & 1.7 & $\varnothing$ & 1084.8 \\
\hline$\overline{0}$ & & Max: & 1.8 & Max: & 1084.9 \\
\hline 苂 & & Min: & 1.6 & Min: & 1084.7 \\
\hline $\bar{Z}$ & LE 2 & $\varnothing$ & 2.1 & $\varnothing$ & 1084.4 \\
\hline $\bar{\Xi}$ & & Max: & 2.2 & Max: & 1084.5 \\
\hline है & & Min: & 2.0 & Min: & 1084.3 \\
\hline & NE $2 *$ & & n.a. & & n.a. \\
\hline & LE 1 & $\varnothing$ & 1.8 & $\varnothing$ & 1084.7 \\
\hline & & Max: & 1.9 & Max: & 1084.9 \\
\hline & & Min: & 1.7 & Min: & 1084.6 \\
\hline & NL 1 & $\varnothing$ & 1.5 & $\varnothing$ & 1085.3 \\
\hline & & Max: & 1.6 & Max: & 1085.4 \\
\hline.$\overline{0}$ & & Min: & 1.4 & Min: & 1085.2 \\
\hline$\dot{0}$ & LE 2 & $\varnothing$ & 2.3 & $\varnothing$ & 1084.5 \\
\hline 0 & & Max: & 2.4 & Max: & 1084.6 \\
\hline U & & Min: & 2.2 & Min: & 1084.4 \\
\hline & NE 2 & $\varnothing$ & 1.5 & $\varnothing$ & 1085.3 \\
\hline & & Max: & 1.5 & Max: & 1085.4 \\
\hline & & Min: & 1.3 & Min: & 1085.2 \\
\hline
\end{tabular}

$\overline{* N L} 2$ in the crossed-acicular ultrastructure map was too narrow for measuring. 
Table S4: Local growth rates (three replicate measurements) under pulsed Sr-labelling aquaculture conditions for the compound composite prismatic (oOSL) layer. Line \# refers to blue numbered lines in Supplementary Fig. 13 where growth measurements were obtained. LE 1 and LE 2 (both 6 days), refer to the first and second labelling periods while NE 1 (12 days) denotes normal Sr conditions inbetween LE 1, LE 2, and NE 2 (either 6 days or 12 days depending on specimen depicted as bold and normal font) describes growth at

5 normal low Sr concentrations after the last labelling event. Specimens K2-06, K2-10 and K2-14 are excluded here as they showed different perturbations at the growth front.

\begin{tabular}{|c|c|c|c|c|c|c|}
\hline Sample ID: & Line \#: & Rep.: & $\begin{array}{c}\text { LE 1 } \\
{[\mu \mathrm{m} / 6 \mathrm{~d}]}\end{array}$ & $\begin{array}{c}\text { NE 1 } \\
{[\mu \mathrm{m} / 12 \mathrm{~d}]}\end{array}$ & $\begin{array}{c}\text { LE } 2 \\
{[\mu \mathrm{m} / 6 \mathrm{~d}]}\end{array}$ & $\begin{array}{c}\text { NE 2 } \\
{[\mu \mathrm{m} / \mathbf{6 d}] \text { or }} \\
{[\mu \mathrm{m} / 12 \mathrm{~d}]}\end{array}$ \\
\hline \multirow[t]{17}{*}{ (A) K2-01 } & 1 & $\mathrm{~A}$ & 5.23 & 5.97 & 0 & 0 \\
\hline & & B & 5.33 & 5.97 & 0 & 0 \\
\hline & & $\mathrm{C}$ & 5.34 & 5.76 & 0 & $\mathbf{0}$ \\
\hline & 2 & A & 5.07 & 5.69 & 0 & $\mathbf{0}$ \\
\hline & & B & 5.20 & 5.72 & 0 & $\mathbf{0}$ \\
\hline & & $\mathrm{C}$ & 5.00 & 5.51 & 0 & $\mathbf{0}$ \\
\hline & 3 & A & 5.97 & 5.39 & 0 & $\mathbf{0}$ \\
\hline & & B & 6.07 & 5.25 & 0 & $\mathbf{0}$ \\
\hline & & $\mathrm{C}$ & 5.96 & 5.11 & 0 & $\mathbf{0}$ \\
\hline & 4 & A & 4.87 & 6.57 & 0 & 0 \\
\hline & & B & 4.68 & 6.75 & 0 & 0 \\
\hline & & C & 4.65 & 6.55 & 0 & $\mathbf{0}$ \\
\hline & 5 & A & 4.48 & 5.13 & 0 & $\mathbf{0}$ \\
\hline & & B & 4.31 & 4.77 & 0 & 0 \\
\hline & & C & 4.38 & 4.98 & 0 & $\mathbf{0}$ \\
\hline & & Ave. & 5.10 & 5.68 & 0 & o \\
\hline & & Stdev. & 0.55 & 0.58 & 0 & 0 \\
\hline \multirow{17}{*}{ (B) $\mathrm{K} 2-02$} & 1 & A & 2.52 & 3.44 & 3.49 & 3.02 \\
\hline & & B & 2.52 & 3.46 & 3.50 & 3.08 \\
\hline & & $\mathrm{C}$ & 2.64 & 3.32 & 3.30 & 2.93 \\
\hline & 2 & A & 2.62 & 4.19 & 2.60 & 3.03 \\
\hline & & B & 2.65 & 4.12 & 2.67 & 3.18 \\
\hline & & C & 2.64 & 4.09 & 2.70 & 3.05 \\
\hline & 3 & A & 2.02 & 4.40 & 2.38 & 2.83 \\
\hline & & B & 1.98 & 4.34 & 2.47 & 2.78 \\
\hline & & $\mathrm{C}$ & 1.91 & 4.33 & 2.34 & 2.85 \\
\hline & 4 & A & 2.07 & 3.06 & 2.02 & 3.01 \\
\hline & & B & 2.19 & 2.83 & 2.27 & 2.93 \\
\hline & & C & 2.07 & 2.94 & 2.07 & 2.91 \\
\hline & 5 & A & 1.68 & 3.70 & 2.34 & 2.29 \\
\hline & & B & 1.77 & 3.68 & 2.34 & 2.18 \\
\hline & & C & 1.72 & 3.64 & 2.28 & 2.21 \\
\hline & & Ave. & 2.20 & 3.70 & 2.58 & 2.82 \\
\hline & & Stdev. & 0.35 & 0.51 & 0.46 & 0.31 \\
\hline \multirow[t]{17}{*}{ (C) $\mathrm{K} 2-04$} & 1 & A & 15.03 & 19.12 & 6.00 & 5.00 \\
\hline & & B & 14.92 & 19.17 & 6.16 & 5.20 \\
\hline & & $\mathrm{C}$ & 14.97 & 19.32 & 6.09 & 5.14 \\
\hline & 2 & A & 12.44 & 20.21 & 4.69 & 7.24 \\
\hline & & B & 12.75 & 20.61 & 4.51 & 7.24 \\
\hline & & C & 12.95 & 20.23 & 4.65 & 7.04 \\
\hline & 3 & A & 13.11 & 19.53 & 4.33 & 5.93 \\
\hline & & B & 13.00 & 19.62 & 4.42 & 5.74 \\
\hline & & C & 13.11 & 19.60 & 4.01 & 5.73 \\
\hline & 4 & A & 12.94 & 19.99 & 4.80 & 5.68 \\
\hline & & B & 13.04 & 20.16 & 4.78 & 5.62 \\
\hline & & C & 13.49 & 19.94 & 4.65 & 5.49 \\
\hline & 5 & A & 12.47 & 20.89 & 4.47 & 5.34 \\
\hline & & B & 12.41 & 20.80 & 4.39 & 5.02 \\
\hline & & C & 12.46 & 20.49 & 4.40 & 5.15 \\
\hline & & Ave. & 13.27 & 19.98 & 4.82 & 5.77 \\
\hline & & Stdev. & 0.90 & 0.56 & 0.66 & 0.75 \\
\hline
\end{tabular}


Table S4 continued.

\begin{tabular}{|c|c|c|c|c|c|c|}
\hline Sample ID: & Line \#: & Rep.: & $\begin{array}{c}\text { LE 1 } \\
{[\mu \mathrm{m} / 6 \mathrm{~d}]}\end{array}$ & $\begin{array}{c}\text { NE 1 } \\
{[\mu \mathrm{m} / 12 \mathrm{~d}]}\end{array}$ & $\begin{array}{c}\text { LE 2 } \\
{[\mu \mathrm{m} / 6 \mathrm{~d}]}\end{array}$ & $\begin{array}{c}\text { NE 2 } \\
{[\mu \mathrm{m} / \mathbf{6 d}] \text { or }} \\
{[\mu \mathrm{m} / 12 \mathrm{~d}]}\end{array}$ \\
\hline \multirow[t]{17}{*}{ (E) K2-08 } & 1 & $\mathrm{~A}$ & 5.76 & 21.47 & 2.17 & 16.59 \\
\hline & & B & 5.64 & 21.17 & 2.20 & 16.57 \\
\hline & & C & 5.65 & 21.15 & 2.12 & 16.45 \\
\hline & 2 & $\mathrm{~A}$ & 8.54 & 24.65 & 2.70 & 15.99 \\
\hline & & B & 8.52 & 24.53 & 2.77 & 16.21 \\
\hline & & $\mathrm{C}$ & 8.44 & 24.57 & 2.73 & 15.95 \\
\hline & 3 & A & 8.89 & 22.21 & 4.16 & 17.30 \\
\hline & & B & 8.74 & 22.33 & 3.96 & 17.48 \\
\hline & & $\mathrm{C}$ & 8.03 & 22.30 & 4.11 & 17.12 \\
\hline & 4 & $\mathrm{~A}$ & 5.20 & 20.15 & 4.13 & 17.10 \\
\hline & & B & 5.13 & 20.07 & 4.43 & 17.32 \\
\hline & & $\mathrm{C}$ & 5.20 & 19.99 & 4.20 & 17.40 \\
\hline & 5 & A & 4.30 & 23.46 & 4.21 & 17.33 \\
\hline & & B & 3.93 & 23.36 & 4.36 & 17.36 \\
\hline & & $\mathrm{C}$ & 4.12 & 23.58 & 4.28 & 17.51 \\
\hline & & Ave. & 6.40 & 22.33 & 3.50 & 16.91 \\
\hline & & Stdev. & 1.81 & 1.59 & 0.89 & 0.54 \\
\hline \multirow[t]{17}{*}{ (F) K2-11 } & 1 & $\mathrm{~A}$ & 1.86 & 8.43 & 1.98 & 5.24 \\
\hline & & B & 1.80 & 8.53 & 2.06 & 5.40 \\
\hline & & $\mathrm{C}$ & 1.89 & 8.57 & 1.99 & 5.33 \\
\hline & 2 & A & 3.28 & 10.30 & 2.99 & 7.59 \\
\hline & & $\mathrm{B}$ & 2.99 & 10.37 & 3.02 & 7.58 \\
\hline & & C & 3.27 & 10.30 & 3.04 & 7.52 \\
\hline & 3 & A & 2.53 & 12.23 & 4.18 & 7.93 \\
\hline & & $\mathrm{B}$ & 2.55 & 12.13 & 4.16 & 7.93 \\
\hline & & $\mathrm{C}$ & 2.54 & 11.71 & 4.02 & 7.96 \\
\hline & 4 & $\mathrm{~A}$ & 3.59 & 12.11 & 4.41 & 8.40 \\
\hline & & $\mathrm{B}$ & 3.81 & 12.17 & 4.59 & 8.23 \\
\hline & & $\mathrm{C}$ & 4.18 & 11.87 & 4.34 & 8.39 \\
\hline & 5 & $\mathrm{~A}$ & 2.74 & 10.88 & 4.18 & 9.35 \\
\hline & & B & 2.74 & 10.95 & 4.19 & 9.28 \\
\hline & & C & 2.81 & 10.88 & 4.18 & 9.36 \\
\hline & & Ave. & 2.84 & 10.76 & 3.55 & 7.70 \\
\hline & & Stdev. & 0.68 & 1.31 & 0.92 & 1.33 \\
\hline
\end{tabular}


Table S5: Local growth rates (three replicate measurements) under pulsed Sr-labelling aquaculture conditions for the crossed-acicular (iOSL) layer. Line \# Line \# as above. LE 1 and LE 2 (both 6 days), refer to the first and second labelling periods while NE 1 (12 days) depicts normal Sr conditions between LE 1, LE 2, and NE 2 (either 6 days or 12 days depending on specimen) describes growth at normal conditions after the last labelling event.

\begin{tabular}{|c|c|c|c|c|c|c|}
\hline Sample ID: & Line \#: & Rep.: & $\begin{array}{c}\text { LE 1 } \\
{[\mu \mathrm{m} / 6 \mathrm{~d}]}\end{array}$ & $\begin{array}{c}\text { NE 1 } \\
{[\mu \mathrm{m} / 12 \mathrm{~d}]}\end{array}$ & $\begin{array}{c}\text { LE } 2 \\
{[\mu \mathrm{m} / 6 \mathrm{~d}]}\end{array}$ & $\begin{array}{c}\text { NE } 2 \\
{[\mu \mathrm{m} / \mathbf{6 d}] \text { or }} \\
{[\mu \mathrm{m} / 12 \mathrm{~d}]}\end{array}$ \\
\hline \multirow[t]{17}{*}{ (A) K2-01 } & 1 & $\mathrm{~A}$ & 3.46 & 3.09 & 3.56 & 3.69 \\
\hline & & B & 3.44 & 3.13 & 3.50 & 3.59 \\
\hline & & $\mathrm{C}$ & 3.37 & 3.03 & 3.82 & 3.66 \\
\hline & 2 & A & 3.23 & 3.80 & 4.06 & 3.23 \\
\hline & & B & 3.14 & 4.02 & 3.80 & 3.20 \\
\hline & & $\mathrm{C}$ & 3.29 & 3.80 & 3.92 & 3.10 \\
\hline & 3 & A & 3.79 & 3.61 & 3.86 & 3.29 \\
\hline & & B & 3.73 & 3.67 & 3.86 & 3.26 \\
\hline & & $\mathrm{C}$ & 3.70 & 3.77 & 3.89 & 3.39 \\
\hline & 4 & A & 3.64 & 3.99 & 4.08 & 3.23 \\
\hline & & B & 3.80 & 3.89 & 4.27 & 3.20 \\
\hline & & $\mathrm{C}$ & 3.61 & 4.05 & 4.27 & 3.16 \\
\hline & 5 & A & 3.48 & 3.79 & 4.11 & 3.29 \\
\hline & & B & 3.38 & 3.86 & 4.24 & 3.36 \\
\hline & & $\mathrm{C}$ & 3.32 & 3.86 & 4.02 & 3.36 \\
\hline & & Ave. & 3.49 & 3.69 & 3.95 & 3.33 \\
\hline & & Stdev. & 0.20 & 0.33 & 0.23 & 0.17 \\
\hline \multirow[t]{17}{*}{ (B) $\mathrm{K} 2-02$} & 1 & A & 4.26 & 4.08 & 3.61 & 2.46 \\
\hline & & B & 3.83 & 3.92 & 3.69 & 2.45 \\
\hline & & $\mathrm{C}$ & 3.91 & 3.82 & 3.77 & 2.47 \\
\hline & 2 & A & 3.58 & 4.59 & 4.24 & 2.94 \\
\hline & & B & 3.32 & 4.73 & 4.10 & 3.20 \\
\hline & & $\mathrm{C}$ & 3.41 & 4.71 & 4.14 & 3.32 \\
\hline & 3 & A & 3.92 & 3.92 & 3.74 & 2.43 \\
\hline & & B & 3.80 & 4.26 & 4.14 & 2.63 \\
\hline & & $\mathrm{C}$ & 3.43 & 3.99 & 3.72 & 2.33 \\
\hline & 4 & A & 3.58 & 4.54 & 3.92 & 2.37 \\
\hline & & B & 3.48 & 4.40 & 4.03 & 3.02 \\
\hline & & $\mathrm{C}$ & 3.53 & 4.38 & 3.75 & 2.29 \\
\hline & 5 & A & 3.29 & 4.40 & 4.03 & 2.34 \\
\hline & & B & 3.34 & 4.32 & 3.89 & 2.45 \\
\hline & & $\mathrm{C}$ & 3.28 & 4.27 & 4.07 & 2.39 \\
\hline & & Ave. & 3.60 & 4.29 & 3.92 & 2.61 \\
\hline & & Stdev. & 0.28 & 0.28 & 0.19 & 0.33 \\
\hline \multirow[t]{17}{*}{ (C) K2-04 } & 1 & $\mathrm{~A}$ & 8.27 & 11.86 & 4.37 & 3.49 \\
\hline & & B & 8.17 & 12.19 & 4.59 & 3.46 \\
\hline & & $\mathrm{C}$ & 9.35 & 12.25 & 4.63 & 3.15 \\
\hline & 2 & A & 3.49 & 9.89 & 4.47 & 2.68 \\
\hline & & B & 3.46 & 9.84 & 4.75 & 2.54 \\
\hline & & $\mathrm{C}$ & 3.15 & 9.59 & 4.75 & 2.80 \\
\hline & 3 & A & 7.88 & 9.96 & 3.64 & 3.39 \\
\hline & & B & 7.82 & 9.87 & 3.64 & 3.46 \\
\hline & & $\mathrm{C}$ & 7.90 & 9.84 & 3.76 & 2.78 \\
\hline & 4 & A & 7.50 & 9.77 & 4.23 & 1.93 \\
\hline & & B & 7.50 & 9.79 & 4.16 & 1.83 \\
\hline & & $\mathrm{C}$ & 7.86 & 9.78 & 4.35 & 1.95 \\
\hline & 5 & A & 7.52 & 9.14 & 4.16 & 1.66 \\
\hline & & B & 7.50 & 9.49 & 4.25 & 1.69 \\
\hline & & $\mathrm{C}$ & 7.73 & 9.26 & 4.42 & 1.52 \\
\hline & & Ave. & 7.01 & 10.17 & 4.28 & 2.55 \\
\hline & & Stdev. & 1.88 & 0.99 & 0.35 & 0.71 \\
\hline
\end{tabular}


Table S5 continued.

\begin{tabular}{|c|c|c|c|c|c|c|}
\hline Sample ID: & Line \#: & Rep.: & $\begin{array}{c}\text { LE 1 } \\
{[\mu \mathrm{m} / 6 \mathrm{~d}]}\end{array}$ & $\begin{array}{c}\text { NE 1 } \\
{[\mu \mathrm{m} / 12 \mathrm{~d}]}\end{array}$ & $\begin{array}{c}\text { LE } 2 \\
{[\mu \mathrm{m} / 6 \mathrm{~d}]}\end{array}$ & $\begin{array}{c}\text { NE 2 } \\
{[\mu \mathrm{m} / \mathbf{6 d}] \text { or }} \\
{[\mu \mathrm{m} / 12 \mathrm{~d}]}\end{array}$ \\
\hline \multirow[t]{17}{*}{ (D) K2-06 } & 1 & $\mathrm{~A}$ & 6.83 & 14.07 & 5.83 & 10.52 \\
\hline & & B & 6.71 & 14.35 & 5.98 & 10.48 \\
\hline & & $\mathrm{C}$ & 6.67 & 14.19 & 5.55 & 10.43 \\
\hline & 2 & A & 6.52 & 14.19 & 5.40 & 10.40 \\
\hline & & B & 6.55 & 13.82 & 5.62 & 9.87 \\
\hline & & $\mathrm{C}$ & 6.56 & 14.18 & 5.42 & 9.73 \\
\hline & 3 & A & 5.47 & 13.80 & 5.47 & 10.01 \\
\hline & & B & 5.49 & 13.80 & 5.50 & 10.11 \\
\hline & & $\mathrm{C}$ & 5.29 & 13.61 & 5.54 & 10.09 \\
\hline & 4 & A & 5.87 & 13.06 & 5.79 & 10.52 \\
\hline & & B & 5.89 & 13.15 & 5.79 & 10.44 \\
\hline & & $\mathrm{C}$ & 5.88 & 12.99 & 5.27 & 10.09 \\
\hline & 5 & A & 5.13 & 12.59 & 5.17 & 9.39 \\
\hline & & B & 5.42 & 12.72 & 5.22 & 9.35 \\
\hline & & $\mathrm{C}$ & 5.40 & 12.79 & 5.27 & 9.31 \\
\hline & & Ave. & 5.98 & 13.55 & 5.52 & 10.05 \\
\hline & & Stdev. & 0.58 & 0.59 & 0.24 & 0.42 \\
\hline \multirow[t]{17}{*}{ (E) $\mathrm{K} 2-08$} & 1 & A & 5.99 & 11.10 & 4.11 & 7.56 \\
\hline & & B & 6.19 & 11.02 & 4.03 & 7.63 \\
\hline & & $\mathrm{C}$ & 6.06 & 11.09 & 4.04 & 7.62 \\
\hline & 2 & A & 5.45 & 11.16 & 3.88 & 7.55 \\
\hline & & B & 5.40 & 11.03 & 3.82 & 7.56 \\
\hline & & $\mathrm{C}$ & 5.42 & 11.16 & 3.75 & 7.50 \\
\hline & 3 & A & 5.04 & 10.79 & 3.30 & 7.48 \\
\hline & & B & 4.89 & 10.79 & 3.16 & 7.48 \\
\hline & & $\mathrm{C}$ & 4.88 & 10.72 & 3.32 & 7.41 \\
\hline & 4 & A & 4.75 & 10.36 & 3.88 & 7.05 \\
\hline & & B & 4.89 & 10.20 & 3.95 & 7.19 \\
\hline & & $\mathrm{C}$ & 4.82 & 10.22 & 3.73 & 7.06 \\
\hline & 5 & A & 4.76 & 10.44 & 3.31 & 6.91 \\
\hline & & B & 4.74 & 10.51 & 3.30 & 6.99 \\
\hline & & $\mathrm{C}$ & 4.89 & 10.44 & 3.45 & 6.98 \\
\hline & & Ave. & 5.21 & 10.74 & 3.67 & 7.33 \\
\hline & & Stdev. & 0.49 & 0.34 & 0.31 & 0.26 \\
\hline \multirow[t]{17}{*}{ (F) $\mathrm{K} 2-10$} & 1 & A & 14.19 & 22.83 & 6.12 & 14.67 \\
\hline & & B & 13.86 & 22.75 & 6.12 & 14.75 \\
\hline & & $\mathrm{C}$ & 13.96 & 22.74 & 6.27 & 14.76 \\
\hline & 2 & A & 13.29 & 24.30 & 6.34 & 16.13 \\
\hline & & B & 13.41 & 24.19 & 6.22 & 16.01 \\
\hline & & $\mathrm{C}$ & 13.49 & 24.31 & 6.32 & 16.03 \\
\hline & 3 & A & 11.76 & 25.66 & 6.96 & 16.52 \\
\hline & & B & 11.74 & 25.88 & 7.07 & 16.53 \\
\hline & & $\mathrm{C}$ & 11.75 & 25.98 & 6.74 & 16.31 \\
\hline & 4 & A & 12.72 & 25.66 & 6.41 & 16.85 \\
\hline & & B & 12.72 & 25.56 & 6.42 & 16.85 \\
\hline & & $\mathrm{C}$ & 12.62 & 25.44 & 6.52 & 16.86 \\
\hline & 5 & A & 12.41 & 25.89 & 6.75 & 16.97 \\
\hline & & B & 12.40 & 25.89 & 6.75 & 17.07 \\
\hline & & $\mathrm{C}$ & 12.73 & 25.89 & 6.65 & 17.18 \\
\hline & & Ave. & 12.87 & 24.86 & 6.51 & 16.23 \\
\hline & & Stdev. & 0.78 & 1.20 & 0.29 & 0.83 \\
\hline
\end{tabular}


Table S5 continued.

\begin{tabular}{|c|c|c|c|c|c|c|}
\hline Sample ID: & Line \#: & Rep.: & $\begin{array}{c}\text { LE 1 } \\
{[\mu \mathrm{m} / 6 \mathrm{~d}]}\end{array}$ & $\begin{array}{c}\text { NE 1 } \\
{[\mu \mathrm{m} / 12 \mathrm{~d}]}\end{array}$ & $\begin{array}{c}\text { LE 2 } \\
{[\mu \mathrm{m} / 6 \mathrm{~d}]}\end{array}$ & $\begin{array}{c}\text { NE 2 } \\
{[\mu \mathrm{m} / \mathbf{6 d}] \text { or }} \\
{[\mu \mathrm{m} / 12 \mathrm{~d}]}\end{array}$ \\
\hline \multirow[t]{17}{*}{ (G) K2-11 } & 1 & A & 6.64 & 11.23 & 4.66 & 8.05 \\
\hline & & B & 6.50 & 11.36 & 4.24 & 7.82 \\
\hline & & C & 6.49 & 11.36 & 4.52 & 7.97 \\
\hline & 2 & A & 6.57 & 11.45 & 4.44 & 7.83 \\
\hline & & B & 6.71 & 11.51 & 4.38 & 7.83 \\
\hline & & $\mathrm{C}$ & 6.63 & 11.52 & 4.31 & 7.62 \\
\hline & 3 & A & 6.21 & 11.86 & 4.59 & 7.41 \\
\hline & & B & 6.42 & 11.86 & 4.52 & 7.55 \\
\hline & & $\mathrm{C}$ & 6.23 & 11.85 & 4.45 & 7.62 \\
\hline & 4 & A & 6.84 & 11.64 & 4.30 & 7.20 \\
\hline & & B & 6.91 & 11.57 & 4.30 & 7.13 \\
\hline & & $\mathrm{C}$ & 6.77 & 11.71 & 4.37 & 7.20 \\
\hline & 5 & A & 7.20 & 11.99 & 4.16 & 7.41 \\
\hline & & B & 6.91 & 11.85 & 4.12 & 7.48 \\
\hline & & C & 6.91 & 11.78 & 4.16 & 7.55 \\
\hline & & Ave. & 6.66 & 11.64 & 4.37 & 7.58 \\
\hline & & Stdev. & 0.26 & 0.22 & 0.16 & 0.27 \\
\hline \multirow[t]{17}{*}{ (H) K2-14 } & 1 & A & 6.42 & 30.16 & 10.91 & 15.42 \\
\hline & & B & 6.06 & 29.80 & 11.05 & 15.40 \\
\hline & & $\mathrm{C}$ & 5.99 & 30.23 & 10.84 & 15.76 \\
\hline & 2 & A & 5.92 & 30.16 & 9.42 & 15.20 \\
\hline & & B & 6.07 & 30.14 & 9.49 & 14.83 \\
\hline & & $\mathrm{C}$ & 6.21 & 30.16 & 9.27 & 15.05 \\
\hline & 3 & A & 7.21 & 31.03 & 8.84 & 14.12 \\
\hline & & B & 7.35 & 30.96 & 8.84 & 14.19 \\
\hline & & $\mathrm{C}$ & 7.20 & 30.96 & 8.77 & 13.98 \\
\hline & 4 & A & 8.35 & 29.95 & 7.70 & 13.90 \\
\hline & & B & 8.20 & 30.23 & 7.63 & 14.26 \\
\hline & & C & 8.56 & 29.95 & 7.70 & 14.05 \\
\hline & 5 & A & 8.63 & 30.37 & 8.25 & 14.55 \\
\hline & & B & 8.84 & 30.02 & 8.27 & 14.40 \\
\hline & & C & 8.77 & 29.95 & 8.20 & 14.48 \\
\hline & & Ave. & 7.32 & 30.27 & 9.01 & 14.64 \\
\hline & & Stdev. & 1.11 & 0.38 & 1.12 & 0.58 \\
\hline
\end{tabular}

\section{References}

5 Pérez-Huerta, A., Cuif, J.-P., Dauphin, Y., and Cusack, M.: Crystallography of calcite in pearls, European Journal of Mineralogy, 26, 507-516, 2014.

Váczi, T.: A new, simple approximation for the deconvolution of instrumental broadening in spectroscopic band profiles,

Applied spectroscopy, 68, 1274-1278, 2014. 